New version: 23/10/2020;

Available online: 14/12/2020; $2^{\text {nd }}$ round notif.: 09/11/2020; Published: 14/12/2020;

\title{
Educação em tempos de pandemia: aspectos afetivos e sociais no processo de ensino e aprendizagem
}

\author{
Title: Education in times of pandemic: affective and social aspects in the teaching and \\ learning process
}

Suzy Kamylla de Oliveira Menezes Universidade Federal de Alagoas suzy.kamylla@gmail.com

\author{
Deise Juliana Francisco \\ Universidade Federal de Alagoas \\ deisej@gmail.com
}

\section{Resumo}

A pandemia por COVID-19 proporcionou mudanças repentinas na sociedade. Esse cenário inesperado e incerto afeta profundamente as instituições educacionais em diversos países, incluindo o Brasil. As Tecnologias Digitais da Informação e Comunicação (TDIC) são apontadas quanto a sua aplicação no ensino a fim de amenizar os impactos da suspensão presencial das aulas, contudo uma série de repercussões sociais e afetivas perpassa as questões educacionais no período de pandemia. Refletir criticamente sobre essas questões é fundamental para contribuir nas estratégias educacionais adotadas durante a pandemia, bem como pós-pandemia. O objetivo deste trabalho é analisar impactos sociais e afetivos sobre o processo ensino-aprendizagem gerados pela pandemia por COVID-19. Para isso, foi realizada uma revisão sistemática da literatura para identificar trabalhos sobre a temática. Foram selecionados 26 trabalhos relacionados com o objetivo da pesquisa. Nos resultados, destacam-se estudos qualitativos e conceituais sobre aspectos sociais e afetivos no contexto educacional, abordando as implicações do ensino online, propostas de métodos de ensino, TDIC a serem aplicadas em ambiente de ensino online ou modelos de ambientes de ensino online. A maioria dos trabalhos é de origem chinesa e tem foco na universidade. Conclui-se que há a necessidade de planejar estratégias que visem lidar com os impactos da pandemia para professores, estudantes, bem como gestão educacional. Esses impactos são afetivos e sociais e envolvem a complexidade dos contextos em que as pessoas estão inseridas. Embora as propostas de plataformas de ensino online se sobressaiam, são necessários estudos sobre as funcionalidades que elas oferecem e como afetam a experiência de ensino-aprendizagem, bem como recursos financeiros para investimento em conectividade de professores e estudantes, além de processos de formação de professores para que se apropriem didaticamente das mesmas.

Palavras-Chave: Educação, Ensino, Aprendizagem, Pandemia, COVID-19, Revisão Sistemática.

\begin{abstract}
The COVID-19 pandemic brought about sudden changes in society. This unexpected and uncertain scenario profoundly affects educational institutions in several countries, including Brazil. Digital Information and Communication Technologies (DICT) are currently widely discussed in terms of their application in teaching, with the statement of mitigating the impacts of face-to-face suspension from classes, however, a series of social and affective repercussions permeate educational issues in the pandemic period. Reflecting critically on these issues is essential to contribute to the educational strategies adopted during the pandemic, as well as post-pandemic. This paper aims to analyze social and affective impacts on the teaching-learning process generated by the pandemic by COVID-19. For this, a systematic literature review was carried out to identify works on the theme, and 26 works related to the research objective were selected. In the results, qualitative and conceptual studies on social and affective aspects in the educational context stand out, addressing the implications of online teaching, proposals for teaching methods, DCIT to be applied in an online teaching environment, or models of online teaching environments. Most of the work is of chinese origin and focuses on the university. It is concluded that there is a
\end{abstract}

Cite as: Menezes, S. K. O. \& Francisco, D. J. (2020). Education in times of pandemic: affective and social aspects in the teaching and learning process (Educação em tempos de pandemia: aspectos afetivos e sociais no processo de ensino e aprendizagem). Brazilian Journal of Computers in Education (Revista Brasileira de Informática na Educação - RBIE), 28, 985-1012. DOI: 10.5753/RBIE.2020.28.0.985 
need to plan strategies to deal with the impacts of the pandemic, for teachers, students, as well as educational management. These impacts are affective and social and involve the complexity of the contexts in which people are inserted. Although the proposals for online teaching platforms stand out, studies are needed on the features they offer and how it affects the teaching-learning experience, as well as financial resources for investing in teacher and student connectivity and teacher training processes to make them didactically appropriate.

Keywords: Education, Teaching, Learning, Pandemic, COVID-19, Systematic Review.

\section{Introdução}

Inicialmente, a pandemia gerada pelo novo coronavírus, é denominada Severe Acute Respiratory Syndrome Coronavirus 2 (SARS-COV-2), também conhecida como COVID-19 (Liang, 2020). Tendo em vista o cenário internacional e o rápido alastramento da doença, o governo brasileiro decretou a Lei $\mathrm{n}^{\mathrm{o}}$ 13.979, de 6 de fevereiro de 2020, incluindo medidas de enfrentamento a nova doença que se configurou como pandemia devido às grandes proporções de alcance mundial e número de mortes causadas (Presidência da República, 2020). No Brasil, o número de casos cresceu aceleradamente sendo que o primeiro caso da doença foi detectado em 26 de fevereiro de 2020. Através da Portaria $\mathrm{n}^{\mathrm{o}}$ 454, de 20 de março de 2020, foi declarado estado de transmissão comunitária do novo coronavírus (Ministério da Saúde, 2020a, 2020b).

Nesse novo cenário, há termos que se tornaram essenciais para entender as medidas restritivas para prevenção da COVID-19: isolamento social, quarentena e distanciamento social. De acordo com a Lei ${ }^{\circ} 13.979$, de 6 de fevereiro de 2020, Art. $2^{\circ}$, considera-se:

I - isolamento: separação de pessoas doentes ou contaminadas, ou de bagagens, meios de transporte, mercadorias ou encomendas postais afetadas, de outros, de maneira a evitar a contaminação ou a propagação do coronavírus; $\mathrm{e}$

II - quarentena: restrição de atividades ou separação de pessoas suspeitas de contaminação das pessoas que não estejam doentes, ou de bagagens, contêineres, animais, meios de transporte ou mercadorias suspeitos de contaminação, de maneira a evitar a possível contaminação ou a propagação do coronavírus.

Conforme Wilder-Smith e Freedman (2020), o distanciamento social é utilizado para reduzir as interações entre pessoas em uma comunidade, as quais podem estar infectadas, mas ainda não foram identificadas com a doença. Além das medidas de higienização - como a lavagem das mãos, uso de máscara e o uso de álcool em gel -, o distanciamento social é considerado uma das principais medidas de prevenção ao contágio por COVID-19. Por isso, as normas e decretos em níveis federal, estadual e municipal foram definidos para tornar essa medida obrigatória.

As Tecnologias Digitais da Informação e Comunicação (TDIC) são atualmente bastante discutidas quanto a sua aplicação no ensino a fim de amenizar os impactos da suspensão presencial das aulas, contudo uma série de repercussões sociais e afetivas perpassam as questões educacionais no período de pandemia. Identificar e refletir criticamente sobre essas questões é fundamental para contribuir nas estratégias educacionais adotadas durante a pandemia, bem como no pós-pandemia.

Conforme Costa, Duqueviz e Pedroza (2015), o termo Tecnologias da Informação e Comunicação (TIC) é comum para tratar de dispositivos eletrônicos e tecnológicos (computador, Internet, smartphone, tablet, etc). Esse termo também inclui tecnologias como televisão e jornal, por exemplo, de modo que há pesquisadores que têm utilizado o termo Novas Tecnologias ou TDIC para se referirem a tecnologias mais recentes.

Com o avanço da pandemia, a educação foi atingida. Em resposta às questões de segurança de saúde pública, as instituições educacionais buscaram ferramentas para auxiliar na transição para as aulas online em caráter excepcional. Esse cenário de crise exige uma reflexão sobre as 
TDIC e como essas podem auxiliar o processo de ensino-aprendizagem, incluindo as pessoas implicadas nos processos educacionais.

Além disso, aspectos de infraestrutura tecnológica (equipamentos, redes de computadores, profissionais de Tecnologia da Informação - TI) nas escolas, universidades e demais instituições educacionais, bem como infraestrutura tecnológica nas residências de estudantes e professores são gargalos que podem influenciar na experiência de ensino-aprendizagem. Também devem ser considerados aspectos referentes ao processo de formação de professores para uso pedagógico das TDIC e compreensão sobre como os estudantes aprendem em meio às dificuldades da pandemia e interação com as TDIC, que não eram comumente utilizadas em sua rotina estudantil. Nesse contexto, a pandemia impacta a educação com a necessidade de se adequar rapidamente a uma realidade de acesso à tecnologia, que ainda não era amplamente utilizada no processo de ensino-aprendizagem.

Este trabalho tem como objetivo analisar impactos sociais e afetivos sobre o processo ensino-aprendizagem gerados pela pandemia por COVID-19. Para isso, foi realizada uma Revisão Sistemática da Literatura (RSL) para identificar trabalhos sobre a temática. Para isso, foram coletadas publicações de quatro bases de dados, a base de dados da SciELO (Scientific Electronic Library Online), do Institute of Electrical and Electronic Engineers (IEEE), da Association for Computing Machinery (ACM) e do Portal de Periódicos da Coordenação de Aperfeiçoamento de Pessoal de Nível Superior (CAPES). Após a seleção, os estudos foram mapeados e classificados de acordo com aspectos determinados. Como consequência, buscou-se fazer um levantamento de quais aspectos sociais e afetivos estão sendo trabalhados na literatura em relação à educação no contexto de pandemia por COVID-19, a partir de questões de pesquisa estabelecidas na RSL.

O presente artigo está organizado da seguinte maneira: a Seção 2 apresenta o aporte teórico referente aos aspectos afetivos da pandemia, aos aspectos sociais e educativos na pandemia e processo ensino-aprendizagem e a COVID-19; na Seção 3 é descrita a abordagem metodológica; na Seção 4 são apresentados os resultados; na Seção 5 são discutidos os resultados; e na Seção 6 são apresentadas as conclusões deste artigo.

\section{Aporte Teórico}

Essa Seção apresenta conceitos para melhor compreensão deste trabalho: aspectos afetivos da pandemia, aspectos sociais e educativos na pandemia, processo ensino-aprendizagem e a COVID-19.

\subsection{Aspectos Afetivos da Pandemia}

Os aspectos afetivos provocados e/ou intensificados pela pandemia são uma das preocupações em relação às mudanças vivenciadas pela sociedade de modo geral, bem como para públicos específicos como estudantes e docentes, de diferentes contextos.

Faro et al. (2020) apontam a necessidade de esforços em todos os níveis e pelas mais diversas áreas do conhecimento com o intuito de minimizar os resultados negativos que a pandemia traz para a saúde mental. Enumo et al. (2020) consideram os fatores estressores que a pandemia por COVID-19 pode acentuar. Os autores colocam em evidência estratégias para lidar com o estresse em tempos de pandemia, direcionadas para o público em geral. Nesse sentido, compartilharam uma cartilha abordando estratégias de enfrentamento do estresse o que pode auxiliar na manutenção do bem-estar emocional. Eles abordam sobre o processo de construção de uma cartilha intitulada "Cartilha para enfrentamento do estresse em tempos de pandemia" de Weide, Vicentini, Araujo, Machado e Enumo (2020).

As repercussões psicológicas causadas pela pandemia podem impactar negativamente na saúde mental, causando estresse pós-traumático e raiva, dentre outros sintomas. Ainda, há o 
medo de adquirir a doença, frustração, tédio, redução do convívio social, perda da rotina usual, sensação de isolamento do resto do mundo, dentre outras situações (Brooks et al. 2020). Devido à pandemia, as mortes de modo acelerado trouxeram formas novas de se deparar com o luto e a perda, por conta de risco de contaminação, mesmo depois do óbito (Crepaldi, Schmidt, Noal, Bolze \& Gabarra, 2020).

Em relação aos impactos afetivos mais amplos na sociedade, no estudo de Bezerra, Silva, Soares e Silva (2020), com uma amostra de 16.440 brasileiros, a partir de questionário online, foi observado o comportamento social das pessoas com relação ao isolamento social imposto pela pandemia da COVID-19. Nos resultados, "27\% disseram que não estavam sentindo nenhum estresse em função do isolamento, $56 \%$ relataram estar sentindo um pouco de estresse e $17 \%$ afirmaram que o isolamento tem gerado muito estresse no ambiente doméstico" (Bezerra et al. p. 2414).

Wang et al. (2020) realizaram um estudo na China para compreender o impacto psicológico da pandemia, a partir de questionário online, aplicado entre 31 de janeiro a 2 de fevereiro de 2020. A pesquisa foi divulgada por redes sociais, primeiro foi disseminada para estudantes universitários e foram encorajados que passassem o questionário para outras pessoas. Participaram da pesquisa 1.210 respondentes, sendo 52,8\% estudantes. Nos resultados foi observado que 53,8\% relataram como moderado ou severo o impacto psicológico; $16,5 \%$ relataram sintomas depressivos severos; $28,8 \%$ relataram sintomas de ansiedade moderado para severo; e 8,1\% relataram níveis de estresse de moderado para severo. Os autores consideraram que a incerteza e o impacto negativo na progressão acadêmica podem ter efeito adverso na saúde mental de estudantes. Desta forma, indicam que durante a pandemia as autoridades educacionais precisam desenvolver portais de atividades online e aplicações web para ministrar aulas e outras atividades de ensino.

No estudo de Johnson, Saletti-Costa e Tumas (2020), os dados foram coletados através de questionário online em dois momentos diferentes entre março e abril de 2020. A primeira coleta foi realizada entre 23 e 25 de março e a segunda, entre 30 de março e 3 de abril, com pessoas maiores de 18 anos e residentes na Argentina. A primeira amostra teve participação de 992 pessoas e a segunda, de 418 pessoas. Foram identificados sentimentos frente à COVID-19, sendo destacados principalmente a incerteza, o medo e a angústia. A incerteza se expressa como um sentimento generalizado de preocupação na população, que se relaciona a uma situação incerta, própria do contexto da pandemia. Esta incerteza gera em algumas pessoas um sentimento de impotência, resignação e falta de controle sobre a situação.

Johnson et al. (2020) também observaram o medo como segundo subtópico mais presente na análise dos dados. O medo se expressou por meio de temor, ansiedade, pânico, que são aspectos que se relacionam ao bem-estar das pessoas pesquisadas. A angústia apareceu com sentimentos que vão desde a tristeza, o aborrecimento, até a depressão. Esses sentimentos também se expressam sobre as situações vivenciadas por outras pessoas, tais como as pessoas queridas e as pessoas em situação de exclusão social.

Ainda, lidar com as mudanças geradas pela pandemia também envolve as consequências positivas que as pessoas consideram que esse momento pode proporcionar, tais como valorização da independência (solidariedade, empatia, união, consciência social), reflexão (autoconhecimento, aprendizagem e crescimento pessoal e coletivo), valorização do meio ambiente (diminuição de poluição, respeito à natureza, cuidado com animais), valorização do Estado e instituições (reconhecimento de profissionais, reconhecimento da saúde pública, valorização do sistema sanitário e científico), valorização dos afetos (laços afetivos, família, amigos), revisão sobre o sistema (mudanças do sistema econômico, laboral, educativo), cuidados com limpeza e higiene (uso de medidas de prevenção à COVID-19), responsabilidade social (atitudes de obediência e cumprimento de normas) (Johnson et al., 2020). 
Pode-se refletir o quanto o contexto da pandemia coloca em evidência aspectos afetivos que são potencializados pelo distanciamento social e suas implicações sobre processos psicológicos das pessoas. Articular e propor estratégias que amenizem os efeitos negativos que o distanciamento social provoca constitui-se necessário tanto no durante, quanto no pós-pandemia, de modo que alguns estudos apontam para a relevância das instituições escolares e uso de TDIC neste contexto.

\subsection{Aspectos Sociais e educativos na Pandemia}

Atualmente, a pandemia por COVID-19 evidenciou vulnerabilidades existentes na sociedade em suas várias dimensões. Aspectos sociais, culturais e políticos se entrelaçam em demandas que emergiram com mais intensidade a partir da pandemia, mas que também revelam problemas sociais que já se manifestavam atenuados ou não.

A pandemia não apresenta apenas consequências negativas sobre as emoções, mas também evidencia uma visão mais ampla sobre o sistema social e político, no qual as pessoas notam mudanças também ligadas à sua posição na sociedade. Perceber possíveis consequências positivas para a sociedade também se entrelaça com o conhecimento sobre os impactos subjetivos para articular uma visão macro sobre questões econômicas, políticas e sociais (Johnson et al., 2020).

Grande parcela da população brasileira que se apresenta em situação de vulnerabilidade, teve sua condição social ainda mais agravada pela necessidade de distanciar-se e com isso estabelecimentos públicos e privados foram restringidos e obrigados a encerrar as atividades temporariamente. Conforme Santos (2020, s/p), "a crise financeira permanente é utilizada para explicar os cortes nas políticas sociais (saúde, educação, previdência social) ou a degradação dos salários. E assim impede que se pergunte pelas verdadeiras causas da crise".

Dentre os vários impactos sociais, podem ser apontadas as repercussões do distanciamento social sobre o trabalho docente e as atividades estudantis. As instituições de ensino de diferentes níveis (ensino básico, ensino superior, ensino tecnológico) se depararam com a inevitabilidade da suspensão das aulas devido à situação de crise sanitária no Brasil. Nesse contexto, cenários distintos das instituições de ensino público e ensino privado são postos em evidência quanto às suas formas de responder a essa demanda urgente.

Barbosa, Viegas e Batista (2020) apontam a busca por alternativas para possibilitar a oferta de aulas aos estudantes, principalmente em instituições privadas, devido à possibilidade de quebra de contrato na relação de consumo ao deixar de ofertar o ensino. Como uma das soluções está o ensino remoto, que é online com aulas em tempo real e utilizado em caráter emergencial, enquanto as aulas presenciais estão suspensas.

No ensino público, grande parte das instituições suspendeu as aulas temporariamente ou aderiu parcialmente a atividades remotas, sendo ainda em caráter experimental sem a necessária infraestrutura e com a maioria dos estudantes que não possui acesso à Internet e equipamentos digitais que permitam acompanhar as atividades remotas. Tanto no ensino público quanto privado, constata-se, em geral, a falta de condições de formação adequada aos professores para adesão a esse formato de ensino, bem como a falta de infraestrutura digital.

A possibilidade de ensino remoto foi normatizada a partir da Portaria $n^{0} 343$ de 17 de março de 2020, emitida pelo Ministério da Educação e Cultura (MEC) para permitir a substituição das aulas presenciais em instituições de ensino superior do país. A Portaria $\mathrm{n}^{0} 544$, de 16 de junho de 2020, revogou essa e as Portarias $n^{\circ} 345$, de 19 de março de 2020 e a $n^{\circ} 473$, de 12 de maio de 2020. De modo que, ficou autorizado em caráter excepcional que aulas presenciais sejam substituídas por atividades que usem recursos de TIC ou outros meios convencionais até dia 31/12/2020 (MEC, 2020a). 
Em 01 de junho de 2020 foi publicado no Diário Oficial da União, Seção 1, pág. 32, a homologação parcial o Parecer CNE/CP n ${ }^{\circ} 5 / 2020$, do Conselho Pleno, do Conselho Nacional de Educação - CNE, o qual aprovou orientações com vistas à reorganização do calendário escolar e à possibilidade de cômputo de atividades não presenciais, para fins de cumprimento da carga horária mínima anual, em razão da pandemia do novo coronavírus (DOU, 2020; MEC, 2020b; ANDES, 2020). Nessa perspectiva, o trabalho docente sofreu mudanças e ressignificações ao se deparar com as possibilidades e desafios de uso de TDIC em suas práticas pedagógicas. Também os estudantes se viram imersos na utilização das tecnologias numa perspectiva educativa e distante do ambiente físico educacional.

Em relação ao trabalho docente, fazer uso de TDIC na prática educacional é um desafio para a maioria dos docentes. Nesse contexto, a capacitação profisssional para utilizar esses recursos tornou-se foco de muitas discussões educacionais, bem como as demandas novas que os docentes se depararam para continuar a ministrar aulas, temporariamente se adequando ao ensino remoto.

Nas discussões sobre o acesso à educação no período de pandemia, tanto no público docente quanto no público estudantil, tornaram-se visíveis as diferenças sociais em relação ao acesso às TDIC. Nesse sentido, instituições públicas de ensino têm realizado pesquisas no intuito de mapear a conectividade dos estudantes e como esses podem ter acesso ao ensino de forma remota, bem como iniciativas que buscam levantar possibilidades de acesso à Internet, doação/empréstimo de computadores e/ou celulares, transmissão de aulas via rádio, dentre outras iniciativas e discussões que visam discutir sobre a retomada às aulas em instituições públicas (Rodrigues, 2020; G1, 2020).

\subsection{Processo Ensino-Aprendizagem e a COVID-19}

O processo de ensino-aprendizagem foi evidenciado no contexto da pandemia, questionamentos sobre como conduzir as aulas tornaram-se o foco das instituições de ensino em todos os países.

$\mathrm{Na}$ sociedade do conhecimento, as relações interpessoais, educacionais e profissionais são descritas em meio às transformações de ordem política, econômica, social, cultural e histórica. Tais mudanças não podem ser compreendidas como passíveis de serem delimitadas com exatidão, mas mesclam-se na proposição de novas linguagens e formas de interação, inclusive com o conhecimento. Este vem sendo compreendido como um conjunto de saberes que não mais se alojam em determinados campos, mas que dialogam ininterruptamente, promovendo transformações e diferentes modos de ver e analisar os fenômenos humanos. Nesse âmbito em permanente ruptura e reconstrução, as TDIC têm sido cada vez mais discutidas na área da educação em termos de sua adoção nos meios educacionais e de sua possibilidade de agilizar, facilitar e promover novas leituras de mundo em escolas e universidades (Scorsolini-Comin, 2014, p. 449).

Ao refletir sobre esse contexto, atualmente desafios quanto à docência têm se colocado para efetivação do modelo de aulas remotas, sendo que questões de ética e privacidade entram no debate da condução de aulas remotas. Conforme Marasca, Yates, Schneider, Feijó e Bandeira (2020),

em tempos de distanciamento social, em que os professores precisaram adaptar suas aulas para um formato totalmente online, aulas, mesmo que transmitidas ao vivo, podem ser gravadas para revisão do conteúdo, fazendo com que o professor não tenha controle dos rumos que essa gravação pode tomar [...] Embora essas situações possam acontecer também no contexto presencial, quando apresentados na prática remota, a disseminação deste conteúdo pode ser ainda maior, tendo em vista a facilidade de já estar disponível de modo digital (Marasca et al. 2020, p. 7)

Ainda, questionamentos surgem quanto aos níveis de interação que são possíveis nos ambientes virtuais. Atualmente, vários aplicativos foram incorporados nas práticas docentes, alguns já voltados para o ensino híbrido e outros passaram a ser alternativas para a comunicação online de grupos para atividades de ensino. Essa utilização imediata e acelerada de ferramentas 
antes nunca ou pouco exploradas por professores e estudantes acentua a necessidade de formação e mapeamento diagnóstico para compreender a realidade do público docente e estudantil.

O Google Sala de Aula (Google Classroom) é uma ferramenta que diversas instituições têm utilizado para conduzir aulas a partir do ensino remoto e o contexto da pandemia popularizou sua aplicação (Antunes, 2020; Rodrigues, 2020; Agência Alagoas, 2020). Além do ensino remoto realizado a partir de Ambientes Virtuais de Aprendizagem (AVA) como o Modular Object-Oriented Dynamic Learning Environment (Moodle) e o Sistema Integrado de Gestão de Atividades Acadêmicas (SIGAA), os quais são utilizados em instituições de ensino públicas brasileiras, para ensino em nível médio, técnico e superior (Rodrigues, 2020; Conceição \& Rocha, 2020; SEDIS, 2020; UFAL, 2020; IFAL, 2020).

Segundo Conceição e Rocha (2020), os sistemas Moodle e SIGAA contribuíram para a manutenção dos estudos no período de isolamento social, devido à pandemia por Coronavírus na UFBA. O SIGAA "tem como funcionalidades um repositório de material didático pedagógico para o docente, acompanhamento das atividades solicitadas, comunicação em fórum entre docentes e discentes" (Conceição \& Rocha, 2020, p. 103). Sobre o Moodle, "a proposta pedagógica deste Ambiente Virtual de Aprendizagem promove o trabalho colaborativo de ensino sem exigir conhecimentos aprofundados em informática" (Conceição \& Rocha, 2020, p. 103).

O Google Meet é outra ferramenta que teve sua aplicação popularizada, passando a ser oferecida pela Google não só para contas institucionais, como também para contas pessoais vinculadas a Google. Ela permite realizar reuniões online, atualmente é utilizada para viabilizar aulas e outras atividades institucionais. Além dessa, há outras plataformas de videoconferência, tais como Zoom e Skype, também populares quanto ao uso durante a pandemia. Conforme Beraldo e Maciel (p. 211), as TDIC apresentam potencialidades,

usar as TDIC para uma videoconferência, a sala de aula pode estar conectada em qualquer ponto do planeta, onde um pesquisador, autor de livro, especialista em determinada área ou até estudantes de outras escolas, podem discutir temas relativos ao conteúdo da disciplina. São ideias que não requerem alto investimento e sim novos métodos para usar as TDIC e a rede de uma forma produtiva e contextualizada.

A realidade acima descrita traz possibilidades interessantes de comunicação e ilustra aplicações de videoconferência na educação. Contudo, o uso dessas tecnologias precisa de reflexão quanto a sua aplicação pedagógica no cotidiano escolar. Nesse sentido, atualmente temse em destaque a modalidade de ensino remoto, fazendo uso de instrumentos como os supramencionados. Conforme Rodrigues (2020), é importante diferenciar EaD (Ensino a Distância) e ensino remoto. $\mathrm{Na} \mathrm{EaD}$, o planejamento e execução de um curso ou de uma disciplina tem um modelo subjacente de educação que embasa as escolhas pedagógicas e organiza os processos de ensino e de aprendizagem. Em tempos de pandemia, o que as instituições educacionais têm realizado optando por continuar ou retomar as atividades por meio da Internet é a adaptação temporária do ensino presencial para o ensino remoto, e isso não é EaD.

Embora, considere-se que os docentes possivelmente já conheçam e dominem o uso de TDIC, não é relevante apenas o uso instrumental de tecnologias na prática docente, isso deve estar agregado à finalidade educacional (Rodrigues, 2020; Costa 2013). A pandemia por COVID-19 mostrou que a educação requer mudanças e de forma simplista atribuir a responsabilidade ao professor não é a solução. É necessário espaço de discussão mais aprofundada sobre a formação de professores e o papel da TDIC em suas práticas pedagógicas. Os professores estão sendo cobrados e responsabilizados por uma série de competências às quais não foram apoiadas anteriormente (Bastos \& Boscarioli, 2020). 
Faltam referenciais teórico-práticos, aparato técnico e tecnológico para a reorganização escolar com base em TDIC para atender ao cenário da pandemia. As limitações em vários aspectos devem ser consideradas: o trabalho docente, aspectos estruturais das instituições escolares (escolas, faculdades, universidades, dentre outras), meios digitais que professores e estudantes têm acesso (Pereira Filho et al., 2020).

Sobre as aulas em universidades e institutos federais durante a pandemia, conforme dados do Ministério da Educação (MEC, 2020c), de 02 de agosto de 2020, das 69 universidades federais brasileiras, $45(65,2 \%)$ estavam com as atividades acadêmicas de graduação totalmente suspensas, 17 (24,6\%) com atividades remotas utilizando TDIC e $7(10,1 \%)$ atividades parciais (Figura 1). Dos 41 Institutos Federais (inclui Institutos Federais, Cefet's e Colégio Pedro II), 28 $(68,2 \%)$ estavam com atividades suspensas e 13 (31,7\%) com atividades remotas (Figura 2).

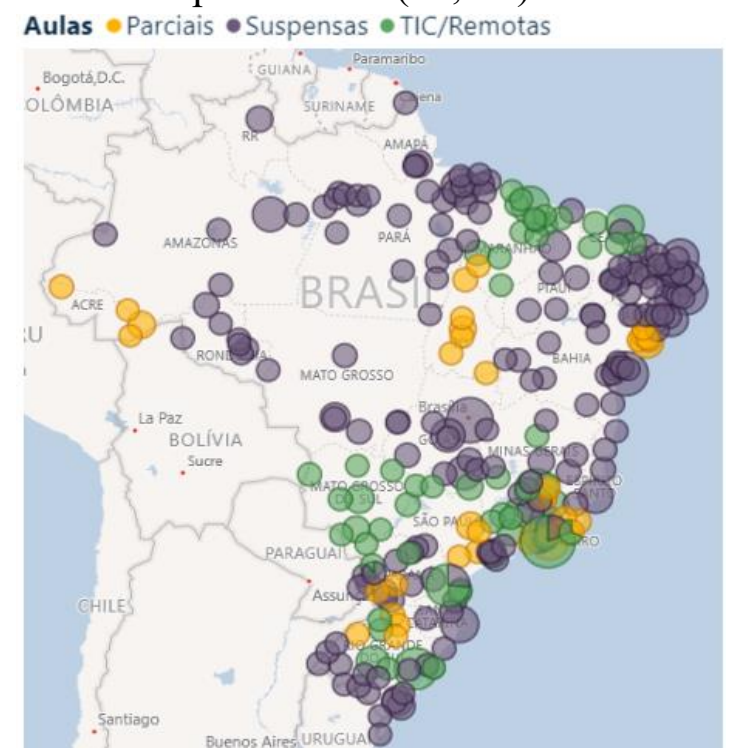

Figura 1 - Mapa do monitoramento das aulas em universidades federais brasileiras. Fonte: MEC (2020c).

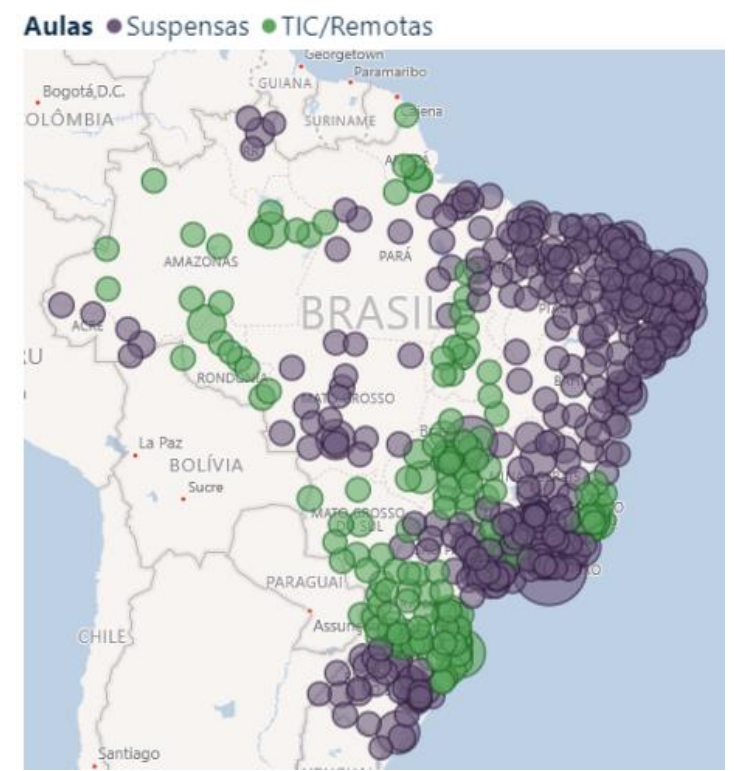

Figura 2 - Mapa do monitoramento das aulas em institutos federais, Cefet's e Colégio Pedro II. Fonte: MEC (2020c).

Nas Figuras 1 e 2, é possível observar o quanto a pandemia impactou na suspensão de atividades educacionais em todo o Brasil, tendo como exemplo a rede pública federal. As TDIC aparecem de forma pontual na manutenção das atividades de ensino. 


\section{Metodologia}

O método utilizado nesta pesquisa é a Revisão Sistemática de Literatura (RSL), que busca identificar, avaliar e analisar trabalhos relevantes para uma questão de pesquisa específica. A revisão teve base no método utilizado por Barcelos (2014) e por Jesus, Silveira e Palanch (2019).

Para a realização deste trabalho foi formulada a seguinte questão de pesquisa primária: Como a pandemia por COVID-19 impactou socialmente e afetivamente os processos de ensinoaprendizagem?

Tendo em vista o período recente de produções sobre a pandemia de COVID-19, foram consideradas as produções recentes publicadas em 2020. A busca foi realizada em 4 bases de dados que foram selecionadas por possuírem diversas publicações nas áreas de Tecnologia, Educação e Saúde:

- SciELO (Scientific Electronic Library Online);

- Portal de Periódicos da Capes;

- IEEE Xplore;

- ACM Digital Library.

\subsection{Questões de Pesquisa (QP)}

Para responder a questão de pesquisa primária: Como a pandemia por COVID-19 impactou socialmente e afetivamente os processos de ensino-aprendizagem?, o trabalho aqui apresentado destrinchou essa pergunta nas seguintes questões de pesquisa secundárias:

- QP1: Quais situações são abordadas sobre os aspectos sociais no processo de ensinoaprendizagem?

- QP2: Quais situações são abordadas sobre os aspectos afetivos no processo de ensinoaprendizagem?

- QP3: Quais tecnologias digitais da informação e comunicação (TDIC) e ferramentas digitais são apontadas para uso no processo de ensino-aprendizagem?

- QP4: Quais são as possibilidades apontadas para lidar com os impactos da pandemia sobre o processo de ensino-aprendizagem?

\subsection{String de Busca}

As bases de dados apresentam resultados através de uma string de busca, isto é, uma cadeia de caracteres formada por um ou mais termos, relacionados por operadores lógicos.

Foi definida a string de busca da seguinte forma: COVID AND (educa* OR estudant* OR alun* OR universi* OR escola OR ensino). A qual foi aplicada na página de busca do SciELO e Portal de Periódicos da CAPES.

Nas bases IEEE Xplore e ACM foi utilizada a string: COVID AND (educa* OR estudent* OR universi* OR school OR teaching). Tendo em vista que essas bases de dados utilizam inglês. As palavras estudantes e alunos foram consideradas equivalentes ao colocar a string em inglês.

\subsection{Critérios de Seleção de Trabalhos Científicos}

Sobre a busca realizada nas bases supracitadas, foram recuperados 970 trabalhos. A Tabela 1 mostra a quantidade de resultados obtidos em cada uma das bases antes e depois de aplicar os critérios de exclusão. 
Tabela 1: Resultado da pesquisa antes e depois da filtragem.

\begin{tabular}{|l|c|c|c|c|c|}
\hline \multicolumn{1}{|c|}{ String } & Base & $\begin{array}{c}\text { Total de } \\
\text { arquivos } \\
\text { recuperados }\end{array}$ & $\begin{array}{c}\text { Após análise de } \\
\text { critérios de } \\
\text { inclusão/exclusão }\end{array}$ & $\begin{array}{c}\text { Após análise } \\
\text { de títulos e } \\
\text { resumos }\end{array}$ & $\begin{array}{c}\text { Após } \\
\text { leitura } \\
\text { integral }\end{array}$ \\
\hline $\begin{array}{l}\text { COVID AND (educa* OR } \\
\text { estudant* OR alun* OR } \\
\text { universi* OR escola OR } \\
\text { ensino) }\end{array}$ & $\begin{array}{c}\text { Periódicos } \\
\text { da Capes }\end{array}$ & 534 & 94 & 4 & 3 \\
\hline $\begin{array}{l}\text { COVID AND (educa* OR } \\
\text { estudent* OR universi* } \\
\text { OR school OR teaching) }\end{array}$ & IEEEXplore & 133 & 21 & 13 & 12 \\
\hline & ACM & 173 & 98 & 10 & 8 \\
\hline
\end{tabular}

Foi necessário definir critérios para identificar os trabalhos a serem analisados, de acordo com sua relevância para esta pesquisa. A seguir são apresentados os critérios aplicados:

- Critérios de inclusão: artigos completos, publicados em periódicos, conferências ou journals; artigos em português, inglês ou espanhol. Considerando a recente pandemia e o período de tempo em que se manifestou mundialmente, foi considerado como período de análise o ano de 2020, no qual foram publicados trabalhos referentes a seus impactos na educação.

- Critérios de exclusão: artigos duplicados, Preprints, e cujo acesso não possa ser realizado de forma gratuita pelos portais consultados através do proxy da universidade de vínculo das pesquisadoras, artigos de magazines, editoriais.

A partir dos critérios supracitados, obteve-se 970 trabalhos. A busca foi realizada em julho de 2020. Não foram observadas repetições de artigos. Foram analisados os títulos e resumos, reduzindo a quantidade de artigos para a leitura completa a 26.

Ressalta-se que cada base de dados apresenta características específicas quanto à visualização dos resultados e foi necessário o uso de filtros conforme a quantidade de resultados obtidos ao aplicar a string de busca. artigos:

Após a leitura integral dos artigos selecionados, foram realizadas classificações sobre os

\section{A. Empírico/Conceitual}

Os trabalhos foram classificados como Empíricos - pesquisas que apresentam experimentos empíricos sobre ambientes de ensino aprendizagem ou trabalhos com amostras populacionais no período de pandemia - e Conceituais - trabalhos que apresentam discussões teóricas referentes ao tema, contendo argumentações baseadas em uma análise sobre o contexto da pandemia por COVID-19 na educação. Os trabalhos que se enquadram como Empírico e Conceitual também foram classificados conforme os itens (B), (C), (D), (E), (F), (G).

\section{B. Público-Alvo}

Esta categoria buscou identificar o público-alvo dos estudos com o nível de educação formal nos estudos que foram realizados.

\section{Instrumentos de Pesquisa}

Nesta categoria buscou-se identificar quais instrumentos de pesquisa foram utilizados para coleta e análise de dados dos trabalhos selecionados. 


\section{Abordagem de Pesquisa}

Refere-se aos tipos de abordagens que foram utilizadas nas pesquisas, tendo como base a descrição do método.

\section{E. Aspectos Sociais e/ou Afetivos Sobre o Processo de Ensino-Aprendizagem}

Buscou-se identificar nos trabalhos argumentação referente aos aspectos sociais e afetivos que envolvem a educação e os processos de ensino-aprendizagem no contexto da pandemia por COVID-19.

\section{F. TDIC e Ferramentas Digitais Apontadas nos Estudos}

Essa categoria buscou identificar nos trabalhos empíricos ou conceituais que tipos de tecnologias são citadas pelos autores no referente às atividades na educação realizadas durante a pandemia.

\section{G. Origem dos Estudos}

Foram identificados os países de origem dos estudos analisados.

\section{Resultados}

No final do artigo consta o Apêndice com a tabela onde estão identificados os artigos desta RSL. Nas tabelas a seguir os mesmos encontram-se classificados e utilizam a numeração atribuída a cada um deles para identificação.

\section{A. Empírico/Conceitual}

A partir da análise dos 26 artigos selecionados foram identificados 15 trabalhos empíricos e 11 trabalhos conceituais (Tabela 2). Esses dados evidenciam a recente busca por estudos para compreender as repercussões da pandemia no contexto educacional, sendo necessários estudos que tragam reflexões sobre como esse fenômeno influencia o processo de ensino-aprendizagem.

Tabela 2: Tipos de pesquisas.

\begin{tabular}{|c|c|c|}
\hline Tipo & Quantidade de Trabalhos & Porcentagem \\
\hline Empírico & {$[2],[3],[5],[7],[8],[9],[10],[11],[12],[14],[16],[18]$,} & $57,69 \%$ \\
& {$[20],[22],[25]$} & \\
\hline Conceitual & {$[1],[4],[6],[13],[15],[17],[19],[21],[23],[24],[26]$} & $42,30 \%$ \\
\hline
\end{tabular}

\section{B. Público Alvo}

A Tabela 3 mostra a divisão de trabalhos por categoria de ensino. Foi observado maior número de trabalhos que se remetem ao Ensino Superior. Pode-se observar na tabela abaixo que os trabalhos [3] e [4] abordam sobre escolas e universidade, por isso foi classificado duas vezes.

Tabela 3: Trabalhos segmentados por categoria de ensino.

\begin{tabular}{|c|c|c|}
\hline Ensino & Trabalhos & Porcentagem \\
\hline Escola & {$[3],[4],[10],[11],[15],[19]$} & $23,07 \%$ \\
\hline Universidade & {$[1],[2],[3],[4],[5],[6],[7],[8],[10],[12],[13],[14],[16]$,} & $73,07 \%$ \\
& {$[18],[20],[21],[22],[23],[25]$} & \\
\hline Não define & {$[17],[24],[26]$} & $11,05 \%$ \\
\hline
\end{tabular}

\section{Instrumentos de Pesquisa}

A Tabela 4 mostra os instrumentos. Devido ao cenário atual em que é necessário o distanciamento social, os pesquisadores buscam ferramentas online que permitem obter dados de modo seguro, bem como atingir maior quantidade de pessoas em um menor espaço de tempo. Ferramentas tais como o Google Forms e Microsoft Forms. 
Tabela 4: Instrumentos de pesquisa utilizados.

\begin{tabular}{|c|c|}
\hline Instrumentos & Trabalhos \\
\hline Questionário online & {$[2],[3],[7],[8],[10],[12],[16],[25]$} \\
\hline Entrevista semiestruturada & {$[20]$} \\
\hline
\end{tabular}

\section{Abordagem de Pesquisa}

Na Tabela 5, quanto à abordagem, foi observado que a maioria dos trabalhos é qualitativa.

Tabela 5: Abordagens de pesquisa utilizadas.

\begin{tabular}{|c|c|}
\hline Abordagem & Trabalhos \\
\hline Experimental & {$[16],[23]$} \\
\hline Survey quantitativo & {$[3],[7],[8],[10],[12],[25]$} \\
\hline Qualitativo & {$[1],[2],[4],[5],[6],[9],[11],[13]$,} \\
& {$[14],[15],[17],[18],[19],[20]$,} \\
\hline
\end{tabular}

\section{E. Aspectos Sociais e/ou Afetivos sobre o Processo de Ensino-Aprendizagem}

Foi observada uma variedade de questões discutidas nos trabalhos selecionados relacionados à educação e ao período de pandemia (Tabela 6).

Tabela 6: Aspectos sociais e/ou afetivos abordados nas pesquisas.

\begin{tabular}{|c|c|}
\hline $\begin{array}{c}\text { Aspectos sociais e/ou afetivos sobre o processo de ensino- } \\
\text { aprendizagem }\end{array}$ & Trabalhos \\
\hline Avaliação psicológica e ensino online & [13] \\
\hline Saúde mental de universitários & {$[12],[25]$} \\
\hline Estilos de aprendizagem, atividades e saúde mental & {$[10]$} \\
\hline $\begin{array}{l}\text { Experiências e expectativas de aprendizagem com a mudança de ensino } \\
\text { presencial para e-learning }\end{array}$ & {$[20]$} \\
\hline Satisfação de estudantes no uso de plataformas online de educação & {$[3]$} \\
\hline Método de ensino (PBL)/ método de ensino (BOPPPS) & {$[18],[2]$} \\
\hline Plataforma de ensino híbrido & {$[23]$} \\
\hline Uso de aula invertida em um ambiente de ensino virtual & [22] \\
\hline Uso de tecnologias baseadas em simulação & {$[21]$} \\
\hline Uso de videoconferência no ensino online & {$[13],[16],[23]$} \\
\hline Plataforma online de ensino musical & [9] \\
\hline Integração entre ensino online e ensino tradicional & [17] \\
\hline $\begin{array}{l}\text { Adaptação no ensino a distância e no ensino presencial devido à } \\
\text { COVID-19 }\end{array}$ & [14] \\
\hline Formação de professores para ensino online & [11] \\
\hline Treinamento e formação profissional durante a pandemia & {$[1]$} \\
\hline Limites e vantagens da educação a distância & [4] \\
\hline Uso de e-learning no ensino & {$[5]$} \\
\hline Aspectos éticos e pedagógicos da e-learning & [24] \\
\hline Impacto psicossomático das ferramentas digitais de e-learning & {$[8]$} \\
\hline Impactos da COVID-19 na educação & {$[6],[7],[19],[26]$} \\
\hline Volta às aulas e a COVID & {$[15]$} \\
\hline
\end{tabular}

\section{F. TDIC e Ferramentas Digitais Apontadas nos Estudos}

Foram observadas as TDIC e as ferramentas digitais citadas pelos autores que foram utilizadas no contexto do ensino-aprendizagem (Tabela 7). 
Tabela 7: Tipos de TDIC apontadas nos estudos.

\begin{tabular}{|c|c|}
\hline TDIC/Ferramentas digitais & Trabalhos \\
\hline Videoconferência, teleconferência & {$[13]$} \\
\hline Videoconferência, AVA & {$[4],[11],[22],[24]$} \\
\hline $\begin{array}{c}\text { Videoconferência, MOOCs, aplicativos de mensagens } \\
\text { instantâneas }\end{array}$ & {$[18]$} \\
\hline Videoconferência, MOOC & {$[6]$} \\
\hline MOOCs, AVA & {$[17]$} \\
\hline Videoconferência, MOOCs, AVA & {$[14]$} \\
\hline Videoconferência, AVA, aplicativo de mensagens \\
instantâneas & {$[16],[23]$} \\
\hline Videoconferência & {$[19]$} \\
\hline Redes sociais, plataforma híbrida & {$[5]$} \\
\hline Sistema de gerenciamento de ensino & {$[3]$} \\
\hline Plataformas online de educação & {$[8]$} \\
\hline Celular, laptop, $i$-pad & {[} \\
\hline
\end{tabular}

\section{G. Origem dos Estudos}

Na Tabela 8, observa-se uma distribuição dos estudos nos seguintes países:

Tabela 8: Origem dos estudos.

\begin{tabular}{|c|c|c|}
\hline País & Quantidade de Trabalhos & Porcentagem \\
\hline Argentina & {$[18]$} & $3,84 \%$ \\
\hline Austria & {$[5]$} & $3,84 \%$ \\
\hline Brasil & {$[13],[15]$} & $7,69 \%$ \\
\hline Canadá & {$[22]$} & $3,84 \%$ \\
\hline China & {$[2],[3],[6],[9],[17],[18],[25],[26]$} & $30,76 \%$ \\
\hline Espanha & {$[14],[20]$} & $7,69 \%$ \\
\hline EUA & {$[1],[11]$} & $7,69 \%$ \\
\hline Índia & {$[10],[16]$} & $7,69 \%$ \\
\hline Itália & {$[4]$} & $3,84 \%$ \\
\hline Irã & {$[21]$} & $3,84 \%$ \\
\hline Jordânia & {$[8]$} & $3,84 \%$ \\
\hline Portugal & {$[7],[12]$} & $7,69 \%$ \\
\hline Rússia & {$[24]$} & $3,84 \%$ \\
\hline Tailândia & {$[23]$} & $3,84 \%$ \\
\hline
\end{tabular}

A maior parte dos estudos foi produzida na China, fato que pode ser explicado devido ao fato da pandemia ter começado nessa localidade.

\section{Discussões}

A partir dos resultados observados através da análise dos artigos, as subseções a seguir buscam elucidar as questões de pesquisa levantadas nesta RSL.

\subsection{Aspectos Sociais no Processo de Ensino-Aprendizagem}

Khattar, Jain e Quadri (2020) abordam como a proposta do ensino online exigiu de muitos estudantes e professores uma mudança abrupta para se adaptarem ao novo cenário imposto pela COVID-19. Os professores tentam adequar suas aulas presenciais para as aulas remotas e isso implica vários desafios relacionados à disponibilidade de recursos, falhas tecnológicas, questões de privacidade e mão de obra qualificada. Os resultados da pesquisa online mostram que dos 583 estudantes indianos, $21,5 \%$ sentem que a aprendizagem online ajuda a manter a rotina e $22 \%$ sentem que aulas online oferecem aprendizagem estruturada durante o confinamento. Também foi observado nas respostas que os estudantes consideram que no ensino online se perde a interação face-a-face, discussão estudantil e atenção pessoal, dentre outros aspectos. Os 
autores concluem que os resultados dos estudantes mostram que o ensino online pode ser complementar ao ensino presencial, mas não substitui a experiência e aprendizado do ambiente de sala de aula e as interações face-a-face.

Chen, Wang e Yang (2020) abordam que os estudantes geralmente consideram que a aprendizagem efetiva não ocorre do mesmo modo que em sala de aula, embora os ambientes de ensino online sejam uma alternativa para não suspender completamente as aulas em escolas e universidades. Ainda, o atual modelo de ensino online é dirigido para complementar o conteúdo básico, sem considerar os reais efeitos sobre a aprendizagem dos estudantes. Alguns aspectos apontados são: objetivos das aulas online não serem suficientemente claros, lacunas na interação online, o interesse dos estudantes em aprender não é tão forte, dentre outros.

Marasca et al. (2020) discutem a viabilidade de processos de Avaliação Psicológica online e apontam direções para seu aperfeiçoamento. Procura-se também apresentar possibilidades para ensino e supervisão a distância. Nesse sentido, são discutidos aspectos éticos sobre a prática de compartilhamento de conteúdo por estudantes de Psicologia, tais como testes psicológicos, conteúdos gravados sem autorização do professor em aulas online, realização de supervisão online.

Vlasov (2020) aborda que é necessário considerar que nem todas as famílias apresentam equipamentos técnicos (quantidade de computadores, conectividade, por exemplo) suficientes para todos os indivíduos de uma família utilizarem nas comunicações no período de distanciamento social. Nuere e Miguel (2020) também apontam que, em relação ao acesso ao computador em casa, devem ser consideradas as situações onde um mesmo equipamento é compartilhado entre estudante e demais familiares, além de problemas de conexões WIFI fracas. Feng, Hu, Fan e Yu (2020) apontam que, ao aderir ao ensino online, há de se considerar os desafios tecnológicos de disponibilidade de plataformas de ensino online para milhares de pessoas, bem como problemas de integração e conexão de dados entre serviços.

Pini (2020) apresenta reflexões sobre a educação no período de pandemia na Argentina. A interrupção das aulas levou os professores a responderem a situação sem planejamento ou preparação prévia para dar continuidade ao ensino e suporte virtual ao processo de aprendizagem. Há inúmeras situações que são colocadas para os professores nesse momento. Aqueles que têm estudantes com acesso à Internet trabalham de casa e enviam instruções aos responsáveis para que colaborem com o ensino das crianças, preparam e colocam materiais online com diferentes conteúdos e atividades para o ensino infantil ou ensino médio e educação superior. Isso é realizado com pouca ou nenhuma experiência. Além disso, a (des)conexão é uma nova dimensão da desigualdade e a crise do coronavírus somente acentua isso. Professores que moram em áreas periféricas, onde muitas não têm Internet, vão para as escolas organizar e distribuir bolsas com comida e colocam nelas tarefas impressas para seus estudantes. Muitos professores de escolas rurais distribuem as atividades escolares casa a casa. Além disso, há o aumento do trabalho dos professores devido ao volume e características dos materiais virtuais, prevalecendo o significado instrumental da tecnologia e em situação de urgência.

Pini (2020) também aponta que há muitos discursos contra os professores e uma valorização das TDIC não sintonizado com a vida dos jovens, e isso foi reproduzido pela mídia. Muitas vezes os professores de muitas formas, mesmo sem recurso suficiente, resistiram às pressões e fizeram o que era possível para lidar com condições desiguais do melhor modo que podiam. Antes da pandemia, havia a pressão para o uso de TDIC e discurso de inovação; desigualdade de acesso a Internet e conectividade; e a dupla jornada de trabalho por parte das mulheres. Com a pandemia, a pressão aumenta e o uso de TDIC torna-se obrigatório; maior carga de trabalho virtualizado; a desigualdade de acesso faz que crianças pobres percam o direito à educação; o trabalho das mulheres aumenta com a carga de trabalho somada ao trabalho doméstico e crianças em casa. 
Xiao e Li (2020) abordam que há perdas irreversíveis de instituições que são obrigadas a fechar por não poderem ofertar cursos online. Além disso, podem ser observados problemas em plataformas de ensino online, embora esse seja o modelo de ensino utilizado para suprir lacunas durante a pandemia. Os problemas em ofertar cursos online estão relacionados à situação de estudantes que não têm computadores ou acesso à Internet, de modo que a pandemia agrava desigualdades educacionais em regiões com diferentes níveis de desenvolvimento econômico.

Ramos-Morcillo, Leal-Costa, Moral-García e Ruzafa-Martínez (2020) investigam as experiências de aprendizagem e as expectativas sobre as mudanças na educação, à luz da mudança abrupta do ensino presencial para o e-learning, de estudantes de enfermagem de bacharelado e mestrado de duas universidades públicas espanholas. Foram realizadas entrevistas semiestruturadas com 32 estudantes, entre março e abril de 2020. Os autores observam que o $e$ learning estabelece limitações para os estudantes mais velhos, para aqueles que vivem em áreas rurais, aqueles que têm responsabilidades profissionais e familiares e aqueles que possuem recursos eletrônicos limitados. $\mathrm{O}$ ensino online permitiu o ensino de teoria, contudo as práticas clínicas se mostraram indispensáveis na formação dos estudantes. Ainda, há a preferência dos estudantes pelo ensino presencial.

Ebner et al. (2020) abordam sobre os procedimentos internos, processos e decisões na Graz University of Technology e aspectos sobre mudanças de comportamento de estudantes e professores, referente a primeira fase da crise causada pela COVID-19, entre o final de fevereiro de 2020 até a primeira semana de abril de 2020. Em relação ao contexto anterior à pandemia, os autores apontam que a maioria das universidades austríacas é de ensino presencial tradicional, sendo que a implementação de estudos híbridos ou apenas online não era muito difundida. $\mathrm{Na}$ universidade citada, foi utilizado o TeachCenter (TC), um sistema de gerenciamento de ensino, para todas as aulas e os seminários, envio de materiais complementares de ensino ou uso para tarefas e comunicação com estudantes. Foi observado que o sistema recebeu 10 vezes mais requisições para novos cursos ofertados online, em relação ao ano de 2019. A mudança para o ensino online foi descrita como um grande desafio, envolvendo altas demandas direcionadas para o departamento de Tecnologia Educacional, além da necessidade de aspectos de infraestrutura para aulas online e comunicação clara e confiança para propor soluções, dentre outros aspectos.

Peng, Li e Fan (2020) consideram que "Internet + Educação" está se tornando um tópico bastante explorado devido à quebra do modelo de ensino tradicional. O modelo de ensino online tem muitos desafios, tais como virtualização do ambiente ensino, mediação do conteúdo de ensino, fragmentação dos recursos de ensino e diversificação dos métodos de ensino. Triyason, Tassanaviboon \& Kanthamanon (2020) propõem que plataformas de ensino híbrido podem ser uma forma de lidar com o ensino durante a pandemia. Contudo, há situações que precisam ser observadas para a construção de sala de aula híbrida, tais como tomar decisões e projetar esse tipo de sistema sob um tempo muito curto. A questão de desigualdade de acesso às TDIC ainda é um dos grandes problemas relacionados à educação online. Desse modo, criar um ambiente de ensino híbrido em condições limitadas é um tópico que se constitui um desafio de pesquisa.

Desse modo, o ensino remoto é uma forma emergencial de manter as atividades de ensino, contudo os estudos apontam a preferência pelo ensino presencial, que remete aos próprios aspectos de socialização que o ambiente escolar e universitário apresenta. A mudança repentina quanto à ausência das instituições educacionais na rotina de estudantes e de professores, afeta as relações sociais que contribuem para o processo de ensino-aprendizagem. Destaca-se o debate quanto às condições de infraestrutura para acesso às tecnologias, que é observada em escala mundial. Esse aspecto traz mudanças quanto à rotina de professores e de estudantes que por questões sociais não acessam as TDIC ou acessam de forma muito precária, aumentando as desigualdades sociais durante a pandemia. 


\subsection{Aspectos Afetivos no Processo de Ensino-Aprendizagem}

Maia e Dias (2020) analisam se os níveis de depressão, ansiedade e estresse em estudantes universitários se alteraram no período pandêmico (2020) comparativamente a períodos anteriores. A amostra foi composta por estudantes universitários portugueses tendo sido observadas variáveis de ansiedade, estresse e depressão em 2018, 2019 e 2020 (período pandêmico). Foram pesquisados dois grupos, a amostra 1 composta por 460 estudantes e a amostra 2 composta por 159 estudantes, tendo sido aplicada a versão portuguesa da Depression, Anxiety and Stress Scales (DASS-21). A comparação entre o período normal (fevereiro e março de 2018 e, depois, em fevereiro e março de 2019) e o período pandêmico (março de 2020, entre a suspensão das aulas e a decretação do estado de emergência em Portugal), mostrou "um aumento significativo de perturbação psicológica (ansiedade, depressão e estresse) entre os estudantes universitários no período pandêmico comparativamente a períodos normais" (Maia, Dias, pp. 6-7).

Khattar et al. (2020) analisam emoções e humor de estudantes indianos. Foi observado que os estudantes têm se adaptado bem a situação de confinamento e têm esperança que a vida volte ao normal em breve. Esse público tem experienciado uma quebra no ensino-aprendizado e as preocupações no momento incluem o calendário incerto de volta às atividades estudantis, admissão no próximo período dos cursos e estágios de verão. Os estudantes de graduação que estão no último ano do curso mostram preocupação com o mercado de trabalho. Ainda sobre o estado emocional de modo geral, identificou-se que há uma mistura de vários tipos de humor: 19,2\% dizem que estão cansados do celular, 42,9\% sentem-se frustrados, muito entediados, ansiosos, sobrecarregados e deprimidos, enquanto $37,9 \%$ sentem-se relaxados, otimistas, calmos e esperançosos.

Wang e Zhao (2020) investigam a ansiedade de estudantes universitários chineses. Foi utilizado questionário online, entre os dias 15 e 17 de fevereiro de 2020 e participaram 3611 estudantes. Foi utilizada a Self-Rating Anxiety Scale (SAS). Os autores observam que os estudantes no início do curso apresentam níveis menores de ansiedade e estudantes mais avançados no curso apresentaram maior nível de ansiedade. Os autores afirmam a partir da análise de outros estudos que os níveis de ansiedade observados nos universitários são maiores que o da população em geral. Por isso, esse aspecto deve ser observado pelos professores em relação às atividades online.

Haider e Al-Salman (2020) examinam o impacto psicossomático das ferramentas digitais de e-learning na pandemia por COVID-19. Os autores obtiveram um total de 775 respostas através de questionário online. Os dados foram analisados de acordo com uma escala Likert, com cinco opções. Conforme os resultados obtidos, 49,9\% dos estudantes concordam fortemente que o uso de ferramentas digitais de aprendizagem é responsável por um baixo rendimento acadêmico; $55,5 \%$ concordam fortemente que o volume de atribuições por meio de e-learning os deixam confusos, frustrados ou com baixo rendimento; 59,6\% concordam fortemente que interação face-a-face contribui significativamente para impulsionar a realização acadêmica; e 41,3\% concordam que passar atividades online para fazer em casa não são confortáveis e os deixam nervosos.

Ferreira, Principe, Pereira, Oliveira e Mota (2020) avaliam o impacto da pandemia por COVID-19 no percurso acadêmico e de vida dos estudantes e sua satisfação com as medidas adotadas. Participaram 264 estudantes da Escola Superior de Saúde Norte da Cruz Vermelha Portuguesa (ESSNorteCVP) e foi aplicado questionário online em maio de 2020. A maioria dos estudantes $(79,2 \%, n=209)$ afirma ter participado de atividades não presenciais, ter acesso a boas condições de plataformas educativas e alta satisfação com o que foi fornecido pela instituição. A plataforma Moodle foi utilizada para inserção de materiais de apoio à aula. O estudo também 
identifica que a maioria dos estudantes $(42,8 \%, \mathrm{n}=113)$ afirma ter sentido maior estresse e ansiedade. Os autores apontam que a referida instituição tomou medidas rápidas para adaptação a ambientes online e acompanhamento docente.

Vlasov (2020) afirma que para o desenvolvimento dos estudantes utilizando sistemas de aprendizagem a distância é necessário um alto nível de autodisciplina, motivação para estudar, equipamentos técnicos apropriados, canais de comunicação, etc. Em relação aos problemas mais óbvios da aprendizagem a distância em comparação a sala de aula pode-se considerar: dificuldade do estudante ter auxílio dos professores; dificuldade dos professores se expressarem para os estudantes; dificuldade do professor alcançar o nível de empatia requerida para compreender os sentimentos e às experiências de cada estudante; maior dificuldade de interação em grupo entre professores e estudantes; maior nível de irritabilidade dos professores devido à alta carga psicológica e de tempo para preparar e conduzir aulas usando TDIC; estresse mental adicional ao trabalhar utilizando computadores, que é maior em pessoas mais velhas; processos de aprendizagem diferentes em aulas a distância e em sala de aula, devido às peculiaridades da percepção da informação obtida por dispositivos técnicos quando comparada a interações interpessoais face-a-face.

Ping, Fudong e Zheng (2020) também apontam alguns problemas no ensino online. Um dos grandes problemas da educação online é a lacuna na interação entre professores e estudantes, sendo necessário buscar meios de viabilizar a interação mesmo de forma virtual. Dentre outros problemas, tais como: os professores não visualizam se os estudantes estão dispersos ou prestando atenção; os estudantes podem não estar aptos a fazerem questionamentos para obter um melhor aprendizado, necessitam de autodisciplina e autocontrole; os estudantes podem se distrair com jogos e a Internet.

Feng et al. (2020) abordam desafios enfrentados pelos professores, tais como a necessidade de aprender como programas funcionam, passar o conteúdo para o ambiente online, adaptar as aulas, problemas relacionados à interação que podem causar grande estresse. Em relação aos estudantes, os autores também apontam que a aprendizagem online requer maior autodisciplina e senso de missão e responsabilidade. Além disso, o ensino online ignora a individualidade e a diversidade da educação.

Nuere e Miguel (2020) abordam o contexto da Universidade Politécnica de Madri e as aulas online foram gravadas para facilitar o acesso aos estudantes. Nas aulas, o uso de câmera foi opcional e os estudantes geralmente não a utilizaram. Esse aspecto dava a sensação aos professores de estarem ensinando sozinhos. O uso de rede social facilitou a comunicação entre estudante e professor. Além disso, foi pontuado que há diferentes especificidades das disciplinas que não são consideradas na mudança para aulas online e precisam ser repensadas.

Telles-Langdon (2020) descreve a experiência dele como professor de uma faculdade usando abordagem de sala de aula invertida em um ambiente de ensino virtual. A mudança para aula online foi observada de modo positivo pelo professor em relação à aceitação dos estudantes e ao rendimento acadêmico. Ainda, aponta que a experiência do mesmo em preparar as aulas online não foi mais árdua que a preparação de aulas convencionais, considerando as possibilidades adaptação ao ensino online.

Ainda, He (2020) em sua proposta de ensino musical online, considera que este apresenta limitações em relação ao ensino tradicional. Existem alguns problemas específicos em relação à performance musical. Um desses problemas está relacionado ao ensino do desempenho musical emocional e técnico. Por exemplo, em cursos de teclado tradicional, professores e estudantes conversam face-a-face ou um a um e podem resolver questões sobre expressões emocionais e habilidades. Os professores podem identificar os problemas que os estudantes apresentam, 
entendê-los e corrigi-los a tempo através de demonstração e explicação, contudo no ensino online não é possível alcançar este efeito.

Assim, sobre aspectos afetivos no processo de ensino-aprendizagem, observa-se que as mudanças de ensino presencial para ensino remoto trazem repercussões sobre a saúde emocional dos estudantes, às quais podem interferir no desempenho escolar ou acadêmico. Os professores também têm seu desempenho influenciado quanto às novas demandas e podem apresentar desgaste psicológico frente ao intenso uso de TDIC. A interação entre estudantes e professores é um dos pontos que mais se destaca quanto às limitações de aulas remotas. Desse modo, os estudos em sua maioria apontam aspectos convergentes quanto às dificuldades de adaptação de professores e de estudantes a essa realidade.

\subsection{Tecnologias e Ferramentas Digitais no Processo de Ensino-Aprendizagem}

Marasca et al. (2020) apontam as possibilidades de utilização de teleconferência e videoconferência no Brasil para a realização de Avaliação Psicológica (AP) online, contudo consideram que há poucos estudos sobre esse tema e reforçam a necessidade de verificação de AP online, sendo seu formato também diferenciado em contextos presenciais e online.

Vlasov (2020) aborda que diversas instituições educacionais no mundo devido à pandemia aderiram a ferramentas como Moodle, Zoom, Business Skype, BigBlueButton, DISCORD, MSTeams e conduziram em grande escala um processo de adesão ao ensino remoto. Na Rússia, quatro abordagens de aprendizagem a distância foram praticadas predominantemente: 1) uso de tecnologias offline para transferência de conteúdo educacional, através de conexões em televisão, telefone e mensagens instantâneas pela Internet; 2) Uso de tecnologia online para transferência de conteúdo utilizando sistema de software de videoconferência (Zoom, Skype, DISCORD, dentre outros); 3) Uso de um ou mais sistemas de aprendizagem a distância (Moodle) para envio de conteúdo educacional em forma de arquivos PDF, conduzir testes online e acesso controlado de usuário; 4) Uso de um ou mais sistemas de aprendizagem a distância (Moodle) para envio de conteúdo educacional em forma de aulas estruturadas e outros tipos de sessões de treinamento com testes offline, recursos multimídia, webinários, fóruns, chats, testes finais online e gerenciamento em alta escala do processo educacional. As três primeiras abordagens oferecem aos estudantes instruções de aulas e não tem uma abordagem sistemática. As ferramentas apontadas na quarta abordagem nem sempre são bem exploradas nos sistemas educacionais.

Triyason, Tassanaviboon e Kanthamanon (2020) discorrem que para a realização de aulas no modelo do ensino híbrido, na Tailândia, são utilizados principalmente quatro plataformas de videoconferência baseadas em nuvem: Google Hangout Meet; Cisco Webex, Zoom e Microsoft Teams. Pal, Vanijja e Patra (2020) mostram um experimento subjetivo com 54 estudantes do terceiro ano de um curso de engenharia, que estavam matriculados nas disciplinas de sistemas de gerenciamento de banco de dados e redes de computadores para avaliar a percepção sobre a qualidade multimídia. Cada estudante utilizou cada uma das seguintes plataformas: Zoom, Microsoft Teams e Cisco Webex. A partir dos resultados gerais apontou-se para um menor desempenho do Microsoft Teams.

Ping et al. (2020) discutem que, na China, escolas e universidades utilizam plataformas online incluindo seus sistemas de sala de aula online, videoconferência e plataformas de educação online, tais como XuetandX, CNMOOC, IMOOC e China University MOOC que fornece uma variedade de cursos disponíveis para o público na China. Muitos professores usaram livestreaming em suas aulas, vídeos gravados e discussões usando aplicativos de mensagens instantâneas, tais como WeChat, QQ ou sistema de conferência online.

Complementando essa afirmação, Peng et al. (2020) apontam que além do uso de plataformas de ensino, tais como China University MOOC, também há a NetEase Open Course, 
Koolearn, Rain Class, Learning Link. Xiao e Li (2020) apontam que a NetEase Cloud Classroom, uma das maiores plataformas de educação online, anunciou o acesso gratuito a cursos para o ensino básico e médio para estudantes chineses durante a pandemia.

Pini (2020) aborda que, na Argentina, os professores utilizam diversas estratégias para a continuidade do ensino, dentre elas: grupos de Facebook e WhatsApp, materiais compartilhados pelo Google Drive, blogs com Blogspot ou plataforma Wix, e maior uso do Google Classroom.

Nuere e Miguel (2020) abordam o contexto da Universidade Politécnica de Madri e discorrem que a universidade tinha à disposição apenas o Moodle. Esse ambiente foi utilizado para postagens de vídeos, por exemplo. O envio de determinados conteúdos pelo Moodle não era possível devido ao tamanho do arquivo, sendo necessário enviar por e-mail. Telles-Langdon (2020), em aulas online nos EUA, utilizou softwares como o Zoom e Desire2Learn.

Domenici (2020) aborda sobre limites e vantagens da educação a distância no ensino de química, em relação ao ensino médio e ensino superior, com o foco na educação a distância no período de pandemia por COVID-19. A autora aponta o uso de plataformas de e-learning (por exemplo, plataforma Moodle), websites projetados para videoconferências (por exemplo, Google Meet, Microsoft Teams, Zoom, Skype) e como a pandemia revelou as limitações das modalidades de ensino baseadas somente em educação a distância. Em relação ao ensino de química, isso fica evidente em relação aos trabalhos práticos do laboratório de química.

Tabatabai (2020) explana sobre os desafios no treinamento clínico devido a COVID-19 e o uso de tecnologia baseada em simulação através de educação virtual para manter a educação médica durante a pandemia. No Irã, a maioria das escolas médicas utilizaram plataformas de aprendizagem virtual, por exemplo, Massive Open Online Courses (MOOCS) através dos sistemas ARMAN e oferecidas experiências de aprendizagem integrada através do National Learning Management System (NAVID). Ainda, foram utilizadas ferramentas como Skype, Zoom e Google Meet. Apesar de sistemas de gerenciamento de aprendizagem online oferecem muitos benefícios, tais como o acesso a conteúdo educacional em qualquer lugar e a qualquer tempo, discussões assíncronas e flexibilidade, o desafio é aplicar o conhecimento teórico ao atender os pacientes. Nesse sentido, ainda há grandes barreiras para o uso de simulação na educação médica, mas o uso desse tipo de programa apresenta possibilidades que dependem de investimento e treinamento.

Ainda, há propostas sobre ensino híbrido. Triyason, Tassanaviboon e Kanthamanon (2020) construíram um programa de sala de aula híbrida usando requisitos para instrução e estudo em ambientes híbridos baseados em estudos, o qual ainda é um estudo preliminar tendo em vista a situação da pandemia. Chen et al. (2020) investigaram a satisfação do usuário em plataformas de educação online. Os dados foram coletados entre fevereiro e março de 2020, foram 712 questionários respondidos. Sobre o uso de plataformas de ensino online, alguns os problemas relatados foram congestionamento de rede, interatividade ao vivo, recursos de aprendizagem insuficiente, registro de conta com falhas, dentre outros. Foi observado que a disponibilidade da plataforma é aspecto forte para a experiência dos usuários.

Em suma, com a pandemia houve um movimento de popularização das TDIC e de ferramentas que permitiram que atividades acadêmicas continuassem. As ferramentas de videoconferência, antes pouco presentes no cotidiano de professores e de estudantes, na pandemia tornaram-se necessárias e até mesmo obrigatórias para aderir ao ensino remoto. As plataformas de ensino e AVA também se destacaram quanto a uma demanda intensa e em grandes proporções. Nesse sentido, é essencial a reflexão e a análise sobre o impacto dessas no ensino remoto, considerando o contexto de emergência em que foram aplicadas. 


\title{
5.4 Possibilidades Mediante os Impactos da Pandemia sobre o Processo de Ensino- Aprendizagem
}

Maia e Dias (2020) apontam que é necessária a atenção sobre os efeitos psicológicos da pandemia e suas repercussões sobre a saúde mental dos estudantes, onde o aprofundamento de discussões e implementação de programas de promoção de competências sociais e emocionais para a população mais jovem, além de estratégias para lidar com episódios traumáticos causados pela pandemia. Também apontam que os níveis elevados de ansiedade, depressão e estresse podem estar associados a outros fatores além da pandemia, como personalidade e apoio social recebido, por exemplo.

Marasca et al. (2020) consideram que a Avaliação Psicológica (AP) online é administrável durante a pandemia de forma limitada e em situações pontuais. É ressaltada a necessidade de pesquisas que demonstrem evidências de validade e de confiabilidade de aplicação de teste de forma remota, bem como tecnologias que tornem segura a condução de AP online.

\begin{abstract}
Ainda, pondera-se que o psicólogo, antes de assumir a realização de um processo de AP online, considere sua capacitação teórica e técnica para a atividade, o que envolve também a competência para o uso de TIC. No contexto do ensino de AP online, estratégias de segurança devem focar em reduzir a chance de disseminação de conteúdos relacionados a testes psicológicos e em aumentar a consciência ética entre estudantes e profissionais da Psicologia. Além do cuidado com o não compartilhamento de dados, o professor de AP deve prezar pela atualidade das informações oferecidas nos cursos de plataformas online. Situações como a pandemia da COVID-19 demonstram como a supervisão a distância pode vir a ser útil para os profissionais da área da AP. Recomenda-se na supervisão as mesmas precauções com sigilo e restrições ao compartilhamento de dados da AP online [...] É relevante ressaltar o papel dos professores e dos supervisores como guardiões da qualidade e da ética na área da AP online (Marasca et al., 2020, p. 9).
\end{abstract}

Bell et al. (2020) refletem sobre a necessidade dos educadores buscarem melhores práticas e métodos baseados em evidências em relação ao ensino e aprendizagem online para que possam ser aplicados na Psicologia em serviços de saúde. A educação a distância oferece oportunidades de colaboração que podem enriquecer a experiência educacional. Ambientes de aprendizagem colaborativos podem fornecer uma forma eficiente para que adquirir conhecimentos específicos de uma disciplina ou treinamentos especializados na área de Psicologia. Nessa perspectiva, também considerar as oportunidades de interagir com colegas de outras instituições e até mesmo outros países, de modo a expandir a diversidade de pensamento e experiência.

Xiao e Li (2020) ponderam que o desenvolvimento de plataformas online necessita que funcionalidades relevantes para o ensino sejam aperfeiçoadas, tais como a estabilidade da plataforma, a apresentação de materiais de ensino e a supervisão durante as aulas. De modo que a experiência do usuário nas plataformas seja aperfeiçoada e melhore a experiência de interação entre professores e estudantes.

Nessa mesma ideia, Feng et al. (2020) consideram que tendo em vista a intensificação do uso de plataformas de ensino online, há a necessidade de avaliar as plataformas possíveis, prover treinamento aos professores, para que possam aprender como utilizar os recursos online, adotar métodos para organizar o ensino. Ainda, as universidades devem desenvolver serviços de suporte aos professores como uma prioridade. É importante enfatizar que o ensino online não é uma simples atividade técnica.

Kim (2020) descreve como um curso de educação infantil foi redesenhado para oferecer aos professores oportunidades para ensinar e aprender de forma online. $\mathrm{O}$ uso de ferramentas para momentos síncronos (videoconferência) e assíncronos (fóruns de discussão) de aula foram utilizadas. Uma limitação em relação ao ensino e aprendizagem online para crianças é a necessidade de disponibilidade e supervisão de um adulto. Além disso, em relação à formação docente infantil, o ensino e aprendizagem utilizando programas online é algo que precisa ser 
considerado, para desenvolvimento de habilidade de uso das tecnologias de ensino online e também na interação com as crianças através desse meio.

Sobre métodos que podem contribuir na interação em ambientes de aprendizagem online, Ping, Fudong e Zheg (2020) apresentam um método de ensino para ensino online, tendo como base o Problem Based Learning (PBL). Essa abordagem consiste na apresentação do conteúdo de ensino em forma de problemas e questões relacionadas para os estudantes analisarem e responderem as questões e resolverem os problemas. Os autores apontam a aplicação desse método no ensino da disciplina de Estrutura de Dados, em cursos de Ciência da Computação.

Chen et al. (2020) abordam como o modelo BOPPPS pode ser aplicado no ensino online para estimular aspectos de participação do estudante. Esse modelo é baseado na teoria construtivista e abordagem comunicativa. Esse modelo é caracterizado por seis estágios: B (Bridge-in) - O (Objective/Outcome) - P (Pre-assessment) - P(Participatory Learning) - P (Postassessment) - S (Summary). Bridge-in requer completar uma tarefa para atrair a atenção e interesse. Objective requer dar claramente objetivos específicos e viáveis. Pre-assessment se refere à compreensão de conhecimento prévio e habilidade do estudante. Participatory Learning refere-se à interação participativa dos estudantes. Post-assessment busca saber se o objetivo da atividade foi alcançado. Summary são as combinações finais para consolidar o que foi aprendido e possível continuidade. Foi realizado um estudo com 55 universitários aplicando o modelo BOPPPS em aulas sobre Excel e 50 universitários não utilizaram o modelo de BOPPPS. Foi observado que os estudantes do grupo em que o modelo foi aplicado apresentaram maior nível de compreensão que o outro grupo. Ainda, He (2020) apresenta um modelo de ensino musical online baseado em interação inteligente. A ideia surgiu com base na prática do ensino online durante o período de pandemia.

Pini (2020) considera que, diante do contexto de pandemia, os professores podem se apropriar e fazer com que os estudantes também se apropriem dos recursos digitais de forma crítica e produtiva. Para um diálogo pedagógico, os professores necessitam de treinamento e colaboração no trabalho institucional, seja em pares ou com pessoas jovens. Com o trabalho frente a uma população estudantil heterogênea, os professores necessitam desenvolver estratégias e usar recursos que tenham influência direta no aperfeiçoamento do trabalho pedagógico, fazer melhor uso dos recursos disponíveis e selecionar materiais para o suporte ao ensino. Nesse sentido, considerar os impactos da pandemia e as vulnerabilidades que afetam principalmente a educação pública. É necessário ampliar espaço de debate público e mobilização da defesa a educação pública para aprofundar a crítica aos modos de produção, circulação e naturalização de discursos que colocam as tecnologias (corporações) no centro do processo educacional. As TDIC não são neutras e são gerenciadas por grandes grupos econômicos.

Peng et al. (2020) consideram os impactos da educação baseada na informação e na virtualização do ensino. Mesmo após a pandemia, estudantes e professores irão utilizar as vantagens da Internet com a educação. Com cenário da pandemia, os professores estão utilizando formas diferentes de ensinar o que também podem enriquecer o uso de tecnologias para melhorar a interação entre estudantes e professores.

Oliveira, Gomes e Barcellos (2020) ponderam sobre o período pós-pandemia e consideram que saída como o ensino remoto, o uso de tecnologias e o aumento de carga horária dificilmente são soluções robustas para lidar com as consequências da interrupção das aulas. Com base na literatura, apontam que embora essas opções sejam incorporadas no cotidiano escolar elas não são suficientes para a recuperação de estudantes mais prejudicados. Sobre a realidade brasileira, no ensino infantil há a necessidade de um diagnóstico dos estudantes como base para retomar as aulas e a atuação pedagógica a partir de ensino estruturado, métodos adequados de alfabetização, uso estratégico de deveres de casa e programas de leitura. Eventos como a 
pandemia evidenciam a fonte e origem de desigualdades que requer políticas intensivas para a Primeira Infância e para os primeiros anos escolares.

Assim, as instituições educacionais passam por um contexto complexo que requer adequações tecnológicas, desafio que já existia antes da pandemia e tornou-se inadiável com a chegada desse fenômeno. Além disso, elas são desafiadas a apresentarem planejamento e estratégias que lidem com as implicações sociais, psicológicas e pedagógicas que envolvem a pandemia, somada a urgência quanto ao uso das TDIC na educação. Desse modo, a capacidade de comunicação e de engajamento dos diferentes sujeitos que atuam nesses espaços (gestão, professores, estudantes, técnicos), bem como a necessidade de investimentos financeiros na educação se tornam essenciais para lidar com os impactos da pandemia.

\section{Conclusão}

O presente trabalho objetivou analisar estudos na literatura acadêmica que abordem sobre impactos sociais e afetivos sobre o processo ensino-aprendizagem gerados pela pandemia por COVID-19. Foi realizada uma revisão sistemática da literatura compreendendo artigos escritos em português, inglês ou espanhol, no ano de 2020. As fontes de dados consultadas para a obtenção destes foram: SciELO, Portal de Periódicos da CAPES, ACM Digital Library e IEEE Xplore. Elas foram selecionadas por terem boa reputação e publicações nas áreas da Educação Saúde e Tecnologia. A busca inicial considerando termos relacionados à educação e COVID-19 forneceu 970 resultados, que após a aplicação dos critérios de inclusão e de exclusão e a análise de títulos e resumos foram reduzidos a 26 trabalhos selecionados para a revisão sistemática.

Foram identificados trabalhos de origens geográficas diversificadas, principalmente, trabalhados de autores chineses. Tendo em vista o recente contexto de pandemia, as publicações são referentes ao ano de 2020. Destacam-se estudos qualitativos e conceituais sobre aspectos sociais e afetivos no cenário educacional. O contexto dos estudos mais frequente foi a universidade abordando sobre as implicações do ensino online, propostas de métodos de ensino e ferramentas a serem aplicadas em ambiente de ensino online ou modelos de ambientes de ensino online.

A partir da literatura, observa-se que a educação em tempos de pandemia passa por um momento sem precedentes, onde se evidenciam as dificuldades e os desafios quanto às alternativas utilizadas para manter atividades de ensino no modelo remoto em vários países. A mera transposição de aulas presenciais para aulas remotas mostra-se inviável tendo-se em vista que cada um desses modelos de ensino tem características específicas. De modo que, são necessárias discussões aprofundadas sobre a condução do ensino durante a pandemia.

Sobre as questões de pesquisa deste trabalho, em relação à questão de pesquisa primária, notam-se os profundos impactos da pandemia por COVID-19 na educação. A impossibilidade de manter aulas presenciais levou as instituições educacionais de vários países, inclusive o Brasil a recorrer às TDIC e ferramentas digitais educacionais para retomarem atividades de ensino. Essas mudanças exigiram e continuarão a exigir cautela e adequação de estudantes, docentes e gestão educacional, enquanto o perigo de contágio continuar. Aspectos afetivos e sociais foram mobilizados quanto a esse processo de adequação às TDIC e ferramentas digitais para o processo de ensino-aprendizagem.

Sobre a QP1, em grande parte dos estudos, em algum momento os autores pontuam questionamentos sobre o acesso às TDIC pelos estudantes, a conectividade, questões estruturais que não são facilmente e nem rapidamente resolvidas, em qualquer país. Isso evidencia que as desigualdades sociais tendem a se agravar com o prolongamento do ensino remoto, sendo necessária a reflexão e construção de estratégias durante a pandemia e pós-pandemia para lidar com esse espaço de tempo em que estudantes estiveram no ensino remoto. Sendo isso mais urgente ainda para os estudantes que estiveram com as aulas suspensas. 
Sobre a QP2, considera-se que nesse intrincado momento de proposição de diversas TDIC para as práticas docentes, os professores precisam de apoio das instituições de ensino para se manterem saudáveis e amparados durante a pandemia. Essa adaptação brusca e obrigatória pode afetar negativamente a experiência docente. A qualidade do ensino-aprendizagem depende de sujeitos que tenham sua autonomia, bem-estar e condições sociais e psicológicas levadas em consideração, principalmente em tempos tão desafiadores e que requerem mais que manter uma ilusória sensação de que a educação está funcionando a qualquer custo, sem os devidos cuidados éticos, psicológicos, pedagógicos e sociais com professores e estudantes.

Sobre a QP3, nota-se que quanto ao uso de TDIC, AVA e outros ambientes de ensino online são utilizados e, principalmente, programas de videoconferências, são as alternativas mais adotadas para tentar complementar o ensino durante a pandemia. Contudo, tais tecnologias proporcionam níveis limitados de interação. Consequentemente, impactando na apropriação delas pelos professores e pelos estudantes.

Sobre a QP4, espera-se que o presente artigo seja uma contribuição para identificar possibilidades em relação ao tema. Conclui-se que há a necessidade de planejar estratégias que visem lidar com os impactos negativos da pandemia, para professores, estudantes, bem como gestão educacional tendo em vista o cenário escolar. Esses impactos são afetivos e sociais e envolvem a complexidade dos contextos em que as pessoas estão inseridas. Embora as propostas de plataformas de ensino online se sobressaiam, são necessários estudos sobre as funcionalidades que elas oferecem e como afetam a experiência de ensino-aprendizagem. Além disso, a pandemia intensifica a necessidade de recursos financeiros para investimento em conectividade de professores e estudantes e de apoio aos processos de formação de professores para que se apropriem didaticamente das TDIC. Desse modo, é necessário um debate crítico realizado pelos diferentes sujeitos que fazem parte dos processos educacionais, uma vez que as propostas de uso de plataformas de ensino online em sua maioria se dão de forma verticalizada e sem planejamentos estratégicos pautados na realidade social.

Este trabalho revela que muito ainda precisa ser feito para a compreensão sobre os impactos afetivos e sociais da pandemia no processo de ensino-aprendizagem. $\mathrm{O}$ crescimento no número de estudos sobre este tema apresenta uma tendência por busca de soluções e debates que contribuam no enfrentamento das consequências da pandemia no Brasil e no mundo.

\section{Agradecimentos}

Ao Instituto Federal de Alagoas (IFAL) pelo apoio à qualificação profissional para realização do Doutorado em Educação da primeira autora e à Coordenação de Aperfeiçoamento de Pessoal de Nível Superior (CAPES) pela Bolsa PNPD da segunda autora.

\section{Referências}

Agência Alagoas. (2020). Parceria entre Seduc e Google cria 180 mil e-mails para professores e alunos de Alagoas. Disponível em: http://www.agenciaalagoas.al.gov.br/noticia/item/33379-parceria-entre-seduc-e-google-cria180-mil-e-mails-para-professores-e-alunos-de-alagoas. [Acesso 10 Jul. 2020].

ANDES. MEC valida diretrizes para ensino durante a pandemia e autoriza que atividades remotas sejam computadas como carga horária. Disponível em: https://www.andes.org.br/conteudos/noticia/mEC-valida-diretrizes-para-ensino-durante-apandemia-e-autoriza-que-atividades-remotas-sejam-computa [Acesso em: 12 jul. 2020]. 
Antunes, A. (2020) Fiocruz. As redes municipais de educação diante da pandemia. Disponível em: $\quad$ https://portal.fiocruz.br/noticia/redes-municipais-de-educacao-diante-dapandemia. [Acesso 10 Jul. 2020].

Bastos, T. B. M. C; \& Boscarioli, C. (2020). Os professores do ensino básico e as tecnologias digitais: uma reflexão emergente e necessária em tempos de pandemia. Horizontes. SBC. Disponível: http://horizontes.sbc.org.br/index.php/2020/04/professores-do-ensino-basico-eas-tecnologias-digitais/. [Acesso 10 Jul. 2020].

Barbosa, A. M., Viegas, M. A. S., \& Batista, R. L. N. F. F. (2020). Aulas presenciais em tempos de pandemia: relatos de experiências de professores do nível superior sobre as aulas remotas. Revista Augusus, 25(51), 255-280, jul./out. doi: 10.15202/1981896.2020v25n51p255 [GS Search]

Barcelos, T. S. (2014). Relações entre o pensamento computacional e a matemática em atividades didáticas de construção de jogos digitais. 2014. Tese de Doutorado em Ensino de Ciências e Matemática, Universidade Cruzeiro do Sul. São Paulo, Brasil. 276 p. [GS $\underline{\text { Search }}$

Beraldo, R. M. F, \& Maciel, D. A. (2016). Competências do professor no uso das TDIC e de ambientes virtuais. Psicologia Escolar e Educacional, 20(2), 209-218. doi: 10.1590/2175353920150202952. [GS Search]

Bezerra, A. C. V, Silva, C. E. M, Soares, F. R. G., \& Silva, J. A. M. (2020). Fatores associados ao comportamento da população durante o isolamento social na pandemia de COVID-19. Ciência \& Saúde Coletiva, 25(Suppl. 1), 2411-2421. Epub June 05, 2020. doi: $\underline{10.1590 / 1413-81232020256.1 .10792020}$ [GS Search]

Brooks, S. K., Webster, R. K., Smith, L. E., Woodland, L., Wessely, S., Greenberg, N., \& Rubin, G. J. (2020). The psychological impact of quarantine and how to reduce it: rapid review of the evidence, The Lancet, 395 (102227), pp. 912-920. doi: 10.1016/S01406736(20)30460-8 [GS Search]

Conceição, M. G., \& Rocha, U. R. (2020). TIC para manutenção dos estudos em período de pandemia na Universidade Federal da Bahia. Folha De Rosto, 6(2), 95-106. doi: $\underline{10.46902 / 2020 \mathrm{n} 2 \mathrm{p} 95-106}$ [GS Search]

Costa, F. A. (2013). O potencial transformador das TIC e a formação de professores e educadores. In: Almeida, M. E. B.; Dias, P.; Silva, B. D. (Org.). Cenários de inovação para educação na sociedade digital. São Paulo: Loyola, p. 47-74. [GS Search]

Costa, S. R. S., Duqueviz, B. C., \& Pedroza, R. L. S. (2015). Tecnologias Digitais como instrumentos mediadores da aprendizagem dos nativos digitais. Psicologia Escolar e Educacional, 19(3), 603-610. doi: 10.1590/2175-3539/2015/0193912. [GS Search]

Crepaldi, M. A., Schmidt, B., Noal, D. S., Bolze, S. D. A., \& Gabarra, L. M. (2020). Terminalidade, morte e luto na pandemia de COVID-19: demandas psicológicas emergentes e implicações práticas. Estudos de Psicologia (Campinas), 37, e200090. Epub June 01, 2020. doi: 10.1590/1982-0275202037e200090. [GS Search]

DOU. (2020). Diário Oficial da União. Despacho de 29 de maio de 2020. Seção 1, Pág. 32. Disponível

em: http://pesquisa.in.gov.br/imprensa/jsp/visualiza/index.jsp?data $=01 / 06 / 2020 \&$ jornal $=515 \& p a$ gina $=32$. [Acesso 10 Jul. 2020]. 
Enumo, S. R. F., Weide, J. N., Vicentini, E. C. C., Araujo, M. F., \& Machado, W. L. (2020). Enfrentando o estresse em tempos de pandemia: proposição de uma Cartilha. Estudos de Psicologia (Campinas), 37, e200065. doi: 10.1590/1982-0275202037e200065. [GS Search]

Faro, A., Bahiano, M. A, Nakano, T. C., Reis, C., Silva, B. F. P., \& Vitti, L. S. (2020). COVID19 e saúde mental: a emergência do cuidado. Estudos de Psicologia (Campinas), 37, e200074. Epub June 01, 2020. doi: 10.1590/1982-0275202037e200074. [GS Search]

G1. (2020). Educação. 60\% dos estados monitoram acesso ao ensino remoto: resultados mostram o 'apagão' do ensino público na pandemia. Disponível em: https://g1.globo.com/educacao/noticia/2020/07/06/60percent-dos-estados-monitoramacesso-ao-ensino-remoto-resultados-mostram-apagao-do-ensino-publico-napandemia.ghtml. [Acesso 08 Jul. 2020].

IFAL. (2020). Instituto Federal de Alagoas. Proen oferta cursos de formação continuada para docentes. Disponível em: https://www2.ifal.edu.br/noticias/proen-oferta-cursos-deformacao-continuada-para-docentes [Acesso 30 Jun. 2020].

Jesus, A. M.; Silveira, I. F.; \& Palanch, W. B. L. (2019). Desenvolvimento do Pensamento Computacional por Meio da Colaboração: uma revisão sistemática da literatura. Revista Brasileira de Informática na Educação, 27(2), 69-90. doi: 10.5753/rbie.2019.27.02.69 [GS Search]

Johnson, M. C., Saletti-Cuesta, L., \& Tumas, N. (2020). Emociones, preocupaciones y reflexiones frente a la pandemia del COVID-19 en Argentina. Ciência \& Saúde Coletiva, 25(Suppl. 1), 2447-2456. Epub June 05, 2020. doi: https://doi.org/10.1590/1413$\underline{81232020256.1 .10472020}$ [GS Search]

Liang, T. (2020). Zhejiang University School of Medicine. Handbook of COVID-19: prevention and treatment. Paris: Unesco. Disponível: http://www.zju.edu.cn/english/2020/0323/c19573a1987520/page.htm. [Acesso 10 Jul. 2020]. [GS Search]

MEC. (2020a). Ministério da Educação. Portaria $n^{\circ}$ 544, de 16 de junho de 2020. Dispõe sobre a substituição das aulas presenciais por aulas em meios digitais, enquanto durar a situação de pandemia do novo coronavirus - Covid-19. Disponível em:

https://www.in.gov.br/en/web/dou/-/portaria-n-544-de-16-de-junho-de-2020-261924872. [Acesso 05 Jul. 2020].

MEC. (2020b). Ministério da Educação. Parecer homologado parcialmente. Reorganização do Calendário Escolar e da possibilidade de cômputo de atividades não presenciais para fins de cumprimento da carga horária mínima anual, em razão da Pandemia da COVID-19. Disponível em:

http://portal.mec.gov.br/index.php?option=com_docman\&view=download\&alias=145011pcp005-20\&category slug=marco-2020-pdf\&Itemid=30192. [Acesso 02 Ago. 2020].

MEC. (2020c). Ministério da Educação. Coronavírus: monitoramento nas instituições de ensino. Disponível em: http://portal.mec.gov.br/coronavirus/. [Acesso 02 Ago. 2020].

Ministério da Saúde. (2020a). Primeiro caso de Covid-19 no Brasil permanece sendo o de 26 de fevereiro. Disponível em: https://www.saude.gov.br/noticias/agencia-saude/47215primeiro-caso-de-covid-19-no-brasil-permanece-sendo-o-de-26-de-fevereiro. [Acesso 02 Ago. 2020].

Ministério da Saúde. (2020b). Portaria $n^{\circ} 454$, de 20 de março de 2020. Declara, em todo o território nacional, o estado de transmissão comunitária do coronavírus (covid-19). 
Disponível em: https://www.in.gov.br/en/web/dou/-/portaria-n-454-de-20-de-marco-de2020-249091587. [Acesso 15 Jul. 2020].

Pereira Filho, A. D., Paula, D. T. C., Pinheiro, I. C. M., Ramos, R. P. G., \& Góes, W. C. N. (2020). Psicologia escolar em tempos de crise sanitária: pandemia da covid-19. Publicação da Comissão de Psicologia na Educação - PSINAED - CRP/15. Disponível em: https://www.crp15.org.br/wpcontent/uploads/2020/06/1593004836021 cartilha_PSICOLOGIA-ESCOLAR-EMTEMPOS-DE-CRISE-SANITA\%C4\%9BRIA COVID19.pdf. [Acesso 05 Jul. 2020].

Presidência da República (2020). Lei $n^{\circ}$ 13.979, de 6 de fevereiro de 2020. Dispõe sobre as medidas para enfrentamento da emergência de saúde pública de importância internacional decorrente do coronavírus responsável pelo surto de 2019. Disponível em: http://www.planalto.gov.br/ccivil 03/ ato2019-2022/2020/lei/113979.htm. [Acesso $15 \mathrm{Jul}$. 2020].

Rodrigues, A. (2020). Ensino remoto na educação superior: desafios e conquistas em tempos de pandemia. Horizontes. Disponível em: http://horizontes.sbc.org.br/index.php/2020/06/ensino-remoto-na-educacao-superior/. [Acesso 05 Jul. 2020].

Santos, B. S. (2020). Coronavírus: tudo que é sólido desmancha no ar. Disponível em: https://blogdaboitempo.com.br/2020/04/02/coronavirus-tudo-o-que-e-solido-desmancha-noar/ [Acesso em: 12 jul. 2020].

SEDIS. (2020). Secretaria de educação a distância. Curso abordará o aprendizado nas Turmas Virtuais do SIGAA. Disponível em: http://sedis.ufrn.br/curso-abordara-o-aprendizado-nasturmas-virtuais-do-sigaa/ [Acesso 10 Jul. 2020].

Scorsolini-Comin, F. (2014). Psicologia da educação e as tecnologias digitais de informação e comunicação. Psicologia Escolar e Educacional, 18(3), 447-455. doi: 10.1590/21753539/2014/0183766 [GS Search]

UFAL. (2020). Universidade Federal de Alagoas. Ufal mantém atividades online para técnicos e docentes durante a pandemia. Disponível em: https://ufal.br/servidor/noticias/2020/4/ufaloferta-atividades-online-para-tecnicos-e-docentes-durante-pandemia [Acesso 10 Jul. 2020].

Wang, C., Pan, R., Wan, X., Tan, Y., Xu, L., Ho, C. S., \& Ho, R. C. (2020). Immediate psychological responses and associated factors during the initial stage of Coronavirus Disease (COVID-19) epidemic among the general population in China. International Journal of Environmental Research and Public Health, 17(5), 1729. doi: 10.3390/ijerph17051729. [GS Search]

Weide, J. N., Vicentini, E. C. C., Araujo, M. F., Machado,W. L., \& Enumo, S. R. F. (2020). Cartilha para enfrentamento do estresse em tempos de pandemia. Campinas: PucCampinas. Disponível em: https://www.puc-campinas.edu.br/wpcontent/uploads/2020/04/cartilha-enfrentamento-do-estresse.pdf. [Acesso 10 Jul. 2020] [GS Search]

Wilder-Smith A., \& Freedman, D. O. (2020), Isolation, quarantine, social distancing and community containment: pivotal role for old-style public health measures in the novel coronavirus (2019-nCoV) outbreak. J Travel Med, 27, p. 1-4. doi: 10.1093/jtm/taaa020. [GS Search] 


\section{Apêndice}

Apêndice - Síntese de informações dos artigos selecionados

\begin{tabular}{|c|c|c|c|c|c|}
\hline Autores & Artigo & País & Ensino & $\begin{array}{l}\text { Aspectos sociais e/ou } \\
\text { afetivos sobre o } \\
\text { processo de ensino- } \\
\text { aprendizagem }\end{array}$ & $\begin{array}{l}\text { TDIC/ } \\
\text { Ferramentas } \\
\text { digitais }\end{array}$ \\
\hline $\begin{array}{l}{[1] \text { Bell et al. }} \\
(2020)\end{array}$ & $\begin{array}{l}\text { Health Service Psychology Education } \\
\text { and Training in the Time of COVID- } \\
\text { 19: Challenges and Opportunities }\end{array}$ & EUA & Universidade & $\begin{array}{l}\text { Treinamento e } \\
\text { formação profissional } \\
\text { durante a pandemia }\end{array}$ & Não define \\
\hline $\begin{array}{l}\text { [2] Chen, Wang } \\
\text { e Yang }(2020)\end{array}$ & $\begin{array}{l}\text { Online Teaching Design of University } \\
\text { Computer Course Based on BOPPPS } \\
\text { Mode }\end{array}$ & China & Universidade & $\begin{array}{l}\text { Método de ensino } \\
\text { (BOPPPS) }\end{array}$ & $\begin{array}{l}\text { Plataforma de } \\
\text { ensino }\end{array}$ \\
\hline $\begin{array}{l}\text { [3] Chen et al. } \\
(2020)\end{array}$ & $\begin{array}{l}\text { Analysis of User Satisfaction with } \\
\text { Online Education Platforms in China } \\
\text { during the COVID-19 Pandemic }\end{array}$ & China & $\begin{array}{l}\text { Escola, } \\
\text { Universidade }\end{array}$ & $\begin{array}{l}\text { Satisfação de } \\
\text { estudantes no uso de } \\
\text { plataformas online de } \\
\text { educação }\end{array}$ & $\begin{array}{l}\text { Plataformas online } \\
\text { de educação }\end{array}$ \\
\hline $\begin{array}{l}\text { [4] Domenici } \\
(2020)\end{array}$ & $\begin{array}{l}\text { Distance Education in Chemistry } \\
\text { during the Epidemic Covid-19 }\end{array}$ & Itália & $\begin{array}{l}\text { Escola, } \\
\text { Universidade }\end{array}$ & $\begin{array}{l}\text { Limites e vantagens } \\
\text { da educação a } \\
\text { distância }\end{array}$ & $\begin{array}{l}\text { Videoconferência, } \\
\text { AVA }\end{array}$ \\
\hline $\begin{array}{l}\text { [5] Ebner et al. } \\
(2020)\end{array}$ & $\begin{array}{l}\text { COVID-19 Epidemic as E-Learning } \\
\text { Boost? Chronological Development and } \\
\text { Effects at an Austrian University } \\
\text { against the Background of the Concept } \\
\text { of "E-Learning Readiness" }\end{array}$ & Áustria & Universidade & $\begin{array}{l}\text { Uso de e-learning no } \\
\text { ensino }\end{array}$ & $\begin{array}{l}\text { Sistema de } \\
\text { gerenciamento de } \\
\text { ensino }\end{array}$ \\
\hline $\begin{array}{l}{[6] \text { Feng, } \mathrm{Hu},} \\
\text { Fan e Yu } \\
(2020)\end{array}$ & $\begin{array}{l}\text { A Brief Discussion About the Impact of } \\
\text { Coronavirus Disease } 2019 \text { on Teaching } \\
\text { in Colleges and Universities of China }\end{array}$ & China & Universidade & $\begin{array}{l}\text { Desafios frente ao } \\
\text { ensino em } \\
\text { universidades }\end{array}$ & $\begin{array}{l}\text { Videoconferência, } \\
\text { MOOC }\end{array}$ \\
\hline $\begin{array}{l}{[7] \text { Ferreira, }} \\
\text { Principe, } \\
\text { Pereira, } \\
\text { Oliveira e Mota } \\
(2020)\end{array}$ & $\begin{array}{l}\text { COVimpact: Pandemia COVID-19 nos } \\
\text { Estudantes do Ensino Superior da } \\
\text { Saúde }\end{array}$ & Portugal & Universidade & $\begin{array}{l}\text { Impactos da COVID- } \\
19 \text { na educação }\end{array}$ & Não define \\
\hline $\begin{array}{l}\text { [8] Haider e Al- } \\
\text { Salman }(2020)\end{array}$ & $\begin{array}{l}\text { Dataset of Jordanian University } \\
\text { Student's Psychological Health } \\
\text { Impacted by Using e-Learning Tools } \\
\text { During COVID-19 }\end{array}$ & Jordânia & Universidade & $\begin{array}{l}\text { Impacto } \\
\text { psicossomático das } \\
\text { ferramentas digitais } \\
\text { de e-learning }\end{array}$ & $\begin{array}{l}\text { Celular, laptop, } i- \\
\text { pad }\end{array}$ \\
\hline [9] He (2020) & $\begin{array}{l}\text { Research on Online Teaching of Music } \\
\text { Performance Based on Diversification } \\
\text { and Intelligence - Take the Online } \\
\text { Music Teaching during the COVID-19 } \\
\text { as an Example }\end{array}$ & China & Escola & $\begin{array}{l}\text { Plataforma online de } \\
\text { ensino musical }\end{array}$ & Não define \\
\hline $\begin{array}{l}{[10] \text { Khattar, }} \\
\text { Jain e Quadri } \\
(2020)\end{array}$ & $\begin{array}{l}\text { Effects of the Disastrous Pandemic } \\
\text { COVID } 19 \text { on Learning Styles, } \\
\text { Activities and Mental Health of Young } \\
\text { Indian Students - A Machine Learning } \\
\text { Approach }\end{array}$ & Índia & Universidade & $\begin{array}{l}\text { Estilos de } \\
\text { aprendizagem, } \\
\text { atividades e saúde } \\
\text { mental }\end{array}$ & Não define \\
\hline$\frac{[11] \mathrm{Kim}}{(2020)}$ & $\begin{array}{l}\text { Learning and Teaching Online During } \\
\text { Covid-19: Experiences of Student } \\
\text { Teachers in an Early Childhood } \\
\text { Education Practicum }\end{array}$ & EUA & Escola & $\begin{array}{l}\text { Formação de } \\
\text { professores para } \\
\text { ensino online }\end{array}$ & $\begin{array}{l}\text { Videoconferência, } \\
\text { AVA }\end{array}$ \\
\hline $\begin{array}{l}{[12] \text { Maia e }} \\
\text { Dias }(2020)\end{array}$ & $\begin{array}{l}\text { Ansiedade, depressão e estresse em } \\
\text { estudantes universitários: o impacto da } \\
\text { COVID-19 }\end{array}$ & Portugal & Universidade & $\begin{array}{l}\text { Saúde mental de } \\
\text { universitários }\end{array}$ & Não define \\
\hline [13] Marasca, & Avaliação Psicológica Online: & Brasil & Universidade & Avaliação psicológica & Videoconferência, \\
\hline
\end{tabular}




\begin{tabular}{|c|c|c|c|c|c|}
\hline $\begin{array}{l}\text { Yates, } \\
\text { Schneider, Feijó } \\
\text { e Bandeira } \\
(2020)\end{array}$ & $\begin{array}{l}\text { Considerações a partir da Pandemia do } \\
\text { Novo Coronavírus (COVID-19) para a } \\
\text { Prática e o Ensino no Contexto a } \\
\text { Distância }\end{array}$ & & & $\begin{array}{l}\text { e ensino online/Uso } \\
\text { de videoconferência }\end{array}$ & teleconferência \\
\hline $\begin{array}{l}{[14] \text { Nuere e }} \\
\text { Miguel }(2020)\end{array}$ & $\begin{array}{l}\text { The Digital/Technological Connection } \\
\text { with COVID-19: An Unprecedented } \\
\text { Challenge in University Teaching }\end{array}$ & Espanha & Universidade & $\begin{array}{l}\text { Adaptação no ensino } \\
\text { a distância e no } \\
\text { ensino presencial } \\
\text { devido à COVID-19 }\end{array}$ & $\begin{array}{l}\text { Videoconferência, } \\
\text { AVA, aplicativo de } \\
\text { mensagens } \\
\text { instantâneas }\end{array}$ \\
\hline $\begin{array}{l}{[15] \text { Oliveira, }} \\
\text { Gomes e } \\
\text { Barcellos } \\
(2020)\end{array}$ & $\begin{array}{l}\text { A Covid-19 e a Volta às Aulas: } \\
\text { Ouvindo as Evidências }\end{array}$ & Brasil & Escola & $\begin{array}{l}\text { Volta às aulas e a } \\
\text { COVID }\end{array}$ & Não define \\
\hline $\begin{array}{l}{[16] \text { Pal, }} \\
\text { Vanijja e Patra } \\
(2020)\end{array}$ & $\begin{array}{l}\text { Online Learning During COVID-19: } \\
\text { Students' Perception of Multimedia } \\
\text { Quality }\end{array}$ & Índia & Universidade & $\begin{array}{l}\text { Uso de } \\
\text { videoconferência no } \\
\text { ensino online }\end{array}$ & Videoconferência \\
\hline $\begin{array}{l}\text { [17] Peng, Li e } \\
\text { Fan }(2020)\end{array}$ & $\begin{array}{l}\text { Research on Information-based } \\
\text { Teaching and its Influence on Future } \\
\text { Education under the Background of } \\
\text { Epidemic Situation }\end{array}$ & China & Não define & $\begin{array}{l}\text { Integração entre } \\
\text { ensino online e ensino } \\
\text { tradicional }\end{array}$ & MOOC, AVA \\
\hline $\begin{array}{l}\text { [18] Ping, } \\
\text { Fudong e Zheng } \\
(2020)\end{array}$ & $\begin{array}{l}\text { Thinking and Practice of Online } \\
\text { Teaching under COVID-19 Epidemic }\end{array}$ & China & Universidade & $\begin{array}{l}\text { Método de ensino } \\
(\mathrm{PBL})\end{array}$ & $\begin{array}{l}\text { Videoconferência, } \\
\text { MOOCs, } \\
\text { aplicativos de } \\
\text { mensagens } \\
\text { instantâneas }\end{array}$ \\
\hline [19] Pini (2020) & $\begin{array}{l}\text { Digital Inequality in Education in } \\
\text { Argentina: How the Pandemic of } 2020 \\
\text { Increased Existing Tensions }\end{array}$ & Argentina & Escola & $\begin{array}{l}\text { Impactos do COVID- } \\
19 \text { na educação }\end{array}$ & Não define \\
\hline $\begin{array}{l}\text { [20] Ramos- } \\
\text { Morcillo, Leal- } \\
\text { Costa, Moral- } \\
\text { García e } \\
\text { Ruzafa- } \\
\text { Martínez (2020) }\end{array}$ & $\begin{array}{l}\text { Experiences of Nursing Students during } \\
\text { the Abrupt Change from Face-to-Face } \\
\text { to e-Learning Education during the } \\
\text { First Month of Confinement Due to } \\
\text { COVID-19 in Spain. }\end{array}$ & Espanha & Universidade & $\begin{array}{l}\text { Experiências e } \\
\text { expectativas de } \\
\text { aprendizagem com a } \\
\text { mudança de ensino } \\
\text { presencial para } e- \\
\text { learning }\end{array}$ & Não define \\
\hline$\frac{[21] \text { Tabatabai }}{(2020)}$ & $\begin{array}{l}\text { Simulations and Virtual Learning } \\
\text { Supporting Clinical Education During } \\
\text { the COVID } 19 \text { Pandemic }\end{array}$ & Irã & Universidade & $\begin{array}{l}\text { Uso de tecnologias } \\
\text { baseadas em } \\
\text { simulação }\end{array}$ & $\begin{array}{l}\text { Videoconferência, } \\
\text { MOOCs, AVA }\end{array}$ \\
\hline $\begin{array}{l}{[22] \text { Telles- }} \\
\text { Langdon }(2020)\end{array}$ & $\begin{array}{l}\text { Transitioning University Courses } \\
\text { Online in Response to COVID-19 }\end{array}$ & Canadá & Universidade & $\begin{array}{l}\text { Uso de aula invertida } \\
\text { em um ambiente de } \\
\text { ensino virtual }\end{array}$ & Videoconferência \\
\hline $\begin{array}{l}\text { [23] Triyason, } \\
\text { Tassanaviboon, } \\
\text { Kanthamanon } \\
(2020)\end{array}$ & $\begin{array}{l}\text { Hybrid Classroom: Designing for the } \\
\text { New Normal after COVID-19 } \\
\text { Pandemic }\end{array}$ & Tailândia & Universidade & $\begin{array}{l}\text { Plataforma de ensino } \\
\text { híbrido/ Uso de } \\
\text { videoconferência }\end{array}$ & Videoconferência \\
\hline $\begin{array}{l}{[24] \text { Vlasov }} \\
(2020)\end{array}$ & $\begin{array}{l}\text { Legal and Pedagogical Aspects of e- } \\
\text { Education }\end{array}$ & Rússia & Não define & $\begin{array}{l}\text { Aspectos éticos e } \\
\text { pedagógicos da } e \text { - } \\
\text { learning }\end{array}$ & $\begin{array}{l}\text { Videoconferência, } \\
\text { AVA }\end{array}$ \\
\hline $\begin{array}{l}{[25] \text { Wang e }} \\
\text { Zhao }(2020)\end{array}$ & $\begin{array}{l}\text { The Impact of COVID-19 on Anxiety } \\
\text { in Chinese University Students }\end{array}$ & China & Universidade & $\begin{array}{l}\text { Saúde mental de } \\
\text { universitários }\end{array}$ & Não define \\
\hline $\begin{array}{l}\text { [26] Xiao e Li } \\
(2020)\end{array}$ & $\begin{array}{l}\text { Analysis on the Influence of the } \\
\text { Epidemic on the Education in China }\end{array}$ & China & Não define & $\begin{array}{l}\text { Impactos do COVID- } \\
19 \text { na educação }\end{array}$ & Não define \\
\hline
\end{tabular}

